JGR Oceans

\author{
RESEARCH ARTICLE \\ 10.1029/2019JC015460 \\ Key Points: \\ - The heat content of the recently \\ ventilated Pacific (RVPh) is strongly \\ controlled by gyre circulation \\ - On timescales shorter than 3-5 years, \\ $\mathrm{RVPh}$ is most sensitive to midlatitude \\ wind stress anomalies \\ - On timescales longer than 3-5 years, \\ $\mathrm{RVPh}$ is most sensitive to midlatitude \\ heat flux anomalies
}

Supporting Information:

- Supporting Information S1

- Movie S1

- Movie S2

- Movie S3

- Movie S4

- Movie S5

- Movie S6

Correspondence to:

D. C. Jones,

dannes@bas.ac.uk

Citation:

Jones, D. C., Boland, E. J., Meijers, A. J. S., Forget, G., Josey, S. A., Sallee, J.-B., \& Shuckburgh, E. (2019).Heat distribution in the Southeast Pacific is only weakly sensitive to high-latitude heat flux and wind stress. Journal of Geophysical Research: Oceans, 124, 8647-8666. https://doi.org/10.1029/ 2019JC015460

Received 8 JUL 2019 Accepted 28 OCT 2019

Accepted article online 11 NOV 2019 Published online 8 DEC 2019

(C)2019. American Geophysical Union. All Rights Reserved.

\section{Heat Distribution in the Southeast Pacific Is Only Weakly Sensitive to High-Latitude Heat Flux and Wind Stress}

\author{
Daniel C. Jones ${ }^{1}$ (D), Emma Boland ${ }^{1}$ (D), Andrew J.S. Meijers ${ }^{1}$ iD , Gael Forget $^{2}$ (D), \\ Simon A. Josey ${ }^{3}$ iD) , Jean-Baptiste Sallee ${ }^{4}$, and Emily Shuckburgh ${ }^{1,5}$ iD
}

${ }^{1}$ British Antarctic Survey, Natural Environment Research Council, Cambridge, UK, ${ }^{2}$ Department of Earth, Atmospheric and Planetary Sciences, Massachusetts Institute of Technology, Cambridge, MA, USA, ${ }^{3}$ National Oceanography Centre, Southampton, UK, ${ }^{4}$ Sorbonne Universités, UPMC Université, LOCEAN-IPSL, Paris,France, ${ }^{5}$ Department of Computer Science and Technology, University of Cambridge, Cambridge, UK

\begin{abstract}
The Southern Ocean features regionally varying ventilation pathways that transport heat and carbon from the surface ocean to the interior thermocline on timescales of decades to centuries, but the factors that control the distribution of heat along these pathways are not well understood. In this study, we use a global ocean state estimate (ECCOv4) to (1) define the recently ventilated interior Pacific (RVP) using numerical passive tracer experiments over a 10-year period and (2) use an adjoint approach to calculate the sensitivities of the RVP heat content (RVPh) to changes in net heat flux and wind stress. We find that $\mathrm{RVPh}$ is most sensitive to local heat flux and wind stress anomalies north of the sea surface height contours that delineate the Antarctic Circumpolar Current, with especially high sensitivities over the South Pacific Gyre. Surprisingly, RVPh is not especially sensitive to changes at higher latitudes. We perform a set of step response experiments over the South Pacific Gyre, the subduction region, and the high-latitude Southern Ocean. In consistency with the adjoint sensitivity fields, RVPh is most sensitive to wind stress curl over the subtropical gyre, which alter isopycnal heave, and it is only weakly sensitive to changes at higher latitudes. Our results suggest that despite the localized nature of mode water subduction hot spots, changes in basin-scale pressure gradients are an important controlling factor on RVPh. Because basin-scale wind stress is expected to change in the coming decades to centuries, our results may have implications for climate, via the atmosphere/ocean partitioning of heat.
\end{abstract}

\section{Introduction}

The Southern Ocean (SO), defined here as the ocean south of $30^{\circ} \mathrm{S}$, accounts for $43 \% \pm 3 \%$ of the oceanic component of anthropogenic carbon dioxide uptake and $75 \% \pm 22 \%$ of oceanic heat uptake over the period 1861-2005, despite only occupying 30\% of global surface ocean area (Frolicher et al., 2015). The SO's ability to absorb and sequester this high fraction of heat and carbon comes from a combination of powerful overlying winds, strong buoyancy fluxes, seasonally refreshed pools of weak stratification, and steeply tilted isopycnals that set up a pathway from the surface ocean into the interior thermocline (Hanawa and Talley, 2001; Herraiz-Borreguero \& Rintoul, 2011; Lumpkin \& Speer, 2007; Russell et al., 2006; Speer et al., 2000; Speer \& Forget, 2013; Talley, 2008). Heat and carbon anomalies are subducted in the pools of weak stratification, referred to collectively as pools of Subantarctic Mode Water (SAMW), where they can be exported into the interior via lateral induction, eddy-induced transport, and advection via the mean flow, ventilating the subtropical thermocline on timescales of decades to centuries, with significant regional variability (Cerovecki et al., 2013; Ito et al., 2010; Iudicone et al., 2007; Jones et al., 2016; Karsten \& Marshall, 2002; Khatiwala et al., 2009; Sabine et al., 2004; Sallee et al., 2010, 2012; Sallee \& Rintoul, 2011; Sarmiento et al., 2004; Liu and Huang, 2012). Here, ventilation refers to the set of processes by which surface ocean properties are able to affect the properties of the interior ocean; it can be considered a consequence of the global ocean's overturning circulation (Cerovecki \& Mazloff, 2015; Marshall \& Speer, 2012).

Despite recent efforts to better understand the regionally specific nature of subduction and ventilation (e.g., Cerovecki et al., 2013; Jones et al., 2016), we still have relatively little knowledge on how regional variations in surface forcing and surface ocean properties can ultimately impact subduction and the properties of the ventilated region. We need a more sophisticated understanding of how changes in the location, magnitude, and variability of surface forcing can impact this critical aspect of the overturning circulation. Improvements 
in this area may be especially helpful for improving projections of future ocean states, as changes in the SO forcing-subduction-ventilation mechanism are expected to have a considerable impact on future climate (Cessi \& Otheguy, 2003; Downes et al., 2009; Lovenduski \& Ito, 2009; Morrison et al., 2011; Sallee et al., 2012).

In order to quantify how regional variations in surface forcing (e.g., net heat flux and wind stress) may affect the heat distribution in the ventilated interior ocean, we perform a set of adjoint sensitivity experiments in an observationally constrained state estimate (i.e., ECCOv4). Our adjoint model produces linear sensitivity fields that feature both spatial and temporal variability, allowing us to identify the specific locations and timescales on which surface forcing anomalies can eventually have especially large impacts on the heat distribution in the ventilated interior. We then use the linear adjoint sensitivity fields to inform the design of several nonlinear step response experiments, allowing us to test the validity of the adjoint predictions and to better understand the chain of mechanisms involved in both the linear and nonlinear responses of the SO to changes in heat flux and wind stress forcing.

Generally, on a selected timescale (e.g., 1 year and 10 years), we can consider the volume of the ocean that has been affected by near-surface properties (e.g., the temperature and salinity characteristics of the mode water formation regions) as having been "ventilated" by advection and mixing. The ventilated volume sits below the mixed layer, such that it is isolated from immediate contact with the surface. This view of ventilation is more general than one that focuses on a specific water mass (e.g., SAMW), although there is significant overlap with the water mass view. In this paper, we consider possible influences on the heat distribution of the ventilated volume in the Eastern Pacific sector of the SO, as defined by a set of numerical passive tracer release experiments carried out in ECCOv4. We focus on the Eastern Pacific ventilated volume in particular because it is an especially efficient export pathway of water from the surface ocean into the interior thermocline, as measured by the passive tracer advection rate in numerical experiments (Jones et al., 2016). For convenience, we refer to the recently ventilated interior Eastern Pacific as the recently ventilated Pacific (RVP) and the heat content of the RVP as RVPh. Although there is overlap between the two, we note that the RVP is more general than the SAMW or any other particular water mass. Because RVPh is fixed in volume for each adjoint experiment, it is a measure of the heat distribution in the target region, as it can be affected by both isopycnal heave that moves heat into and out of the RVP and by along-isopycnal heat transport.

In section 2, we describe the ECCOv4 model setup, our definition of the recently ventilated Pacific, and the design of our adjoint sensitivity experiments. In section 3, we present the results of both the adjoint sensitivity experiments and the forward, nonlinear wind stress step response experiments. In section 4, we relate our results to other areas and explore uncertainties. In section 5, we offer a brief summary and conclusions.

\section{Methods}

In section 2.1, we briefly describe the ECCOv4 global ocean state estimate used in this work. In section 2.2, we describe how the control volume, that is, the recently ventilated Southeast Pacific, is defined, and in section 2.3 , we describe the design of the adjoint sensitivity experiments.

\subsection{The ECCOv4 State Estimate}

We use the modeling setup associated with ECCOv4 (Release 2, hereafter ECCOv4-r2 or just ECCOv4). ECCOv4 is a state estimate, meaning that it has been adjusted to minimize the misfits between the model state and a suite of observations from various sources over the time period 1992-2011 (e.g., Argo temperature and salinity profiles, ship hydrography, and satellite altimetry). No artificial sources or sinks of heat were used in the ocean interior; only the model's initial conditions, surface forcing fields, and mixing parameters have been adjusted in order to reduce model-data misfit. The model setup is available for download at GitHub (https://github.com/gaelforget/ECCOv4) as an instance of the open source MIT general circulation model (MITgcm, http://mitgcm.org/, also available at GitHub). We briefly describe the relevant features of the ECCOv4 setup below; a more thorough description is available in Forget, Campin et al. (2015) and references therein.

ECCOv4 is a global ocean model that uses a Lat-Lon-Cap (LLC) grid referred to as LLC90. Its horizontal grid size ranges from around $40-50 \mathrm{~km}$ at high latitudes up to roughly $110 \mathrm{~km}$ at the equator. It features parameterized diffusion, including both diapycnal and isopycnal components, simple convective adjustment, and the Gaspar-Gregoris-Lefevre mixed layer turbulence closure scheme (Gaspar et al., 1990). To represent the 
along-isopycnal effect of unresolved eddies, Forget, Campin, et al. (2015) used a bolus transport parameterization Gent and Mcwilliams (1990, hereafter GM). Although the horizontal resolution of ECCOv4 is relatively coarse (roughly $1^{\circ}$ ), its mixing properties are in good agreement with observations, thanks in part to the use of optimized, spatially varying turbulent transport coefficients (Forget, Ferreira, et al., 2015). ECCOv4 features fully interactive dynamic sea ice, so that buoyancy and mass fluxes at the sea surface are recalculated based on the thermodynamic balance of Losch et al. (2010). Open ocean rain, evaporation, and runoff simply carry (advect through the free surface) the local sea surface temperature and a salinity value of 0 , and runoff is provided by a monthly climatology (Fekete et al., 2002). ECCOv4 calculates buoyancy, radiative, and mass fluxes using the bulk formulae of Large and Yeager (2009) with 6-hourly ERA-Interim reanalysis fields (Dee et al., 2011) as a "first guess" for the forcing fields. Specifically, we use wind stress, 2-m air temperature, 2-m specific humidity, wind speed, downward longwave radiation, and downward shortwave radiation as model inputs. These atmospheric state fields have been iteratively adjusted by the state estimation process in order to minimize model-data misfits. The ECCOv4-r2 setup that we use here does not use surface salinity restoring. For additional validation information, see the supporting information (Figure S1) and Forget, Campin et al. (2015).

\subsection{The Control Volume}

We use a combination of physical state variables and numerical passive tracer distributions to identify the recently ventilated interior ocean in our global model. We initialize passive tracer in selected areas with weak stratification (i.e., low values of potential vorticity) at the base of the mixed layer, using a mixed layer definition based on the density change associated with a temperature variation $\Delta T=0.8^{\circ} \mathrm{C}$ (Kara et al., 2003). Specifically, for each year we initialize the tracer in regions with September-October mean mixed layer depths (MLDs) greater than $300 \mathrm{~m}$ for that year (Figure 1, green dashed lines) with potential vorticity values smaller than an annual minimum potential vorticity threshold. We initialize the tracer from the surface down to the annual maximum MLD. We integrate the tracer equations forward for 10 years, in "online" mode simultaneously with the momentum, buoyancy, and physical tracer equations. Note that although the bulk of the tracer originates in the Pacific, a smaller fraction also comes from the Indian and Atlantic sectors. All releases start on 1 January; our method of initializing tracer above the annual maximum MLD ensures that variations with seasonal release timings are minimal. We performed a release timescale sensitivity test and found that the variability in annual mean tracer distribution associated with the month of tracer release is much smaller than the variability associated with the year of tracer release (not shown). We release the tracer in six different ensemble runs, with release years from 1996 to 2001. In order to define the RVP, we use the 10-year integrated tracer distribution and some additional physical and geographical criteria, selecting grid cells that satisfy the following four conditions:

- be located below the maximum mixed layer over the entire ECCOv4-r2 period (1992-2011)

- time-integrated tracer concentration is at least $10 \%$ of the global ocean maximum value

- be located in the Southeast Pacific, between $170-60^{\circ} \mathrm{W}$ and $60-20^{\circ} \mathrm{S}$

- potential density is greater than or equal to $26.9 \sigma_{0}$

The resulting control volume is located roughly between 300 and $500 \mathrm{~m}$; the areal extent of the RVP changes with depth, reaching its maximum areal extent between 500 and $700 \mathrm{~m}$, covering a large fraction of the South Pacific Gyre (SPG; Figure 1). For more information on the tracer experiments and the resulting distribution, see our companion paper. Note that the use of a fixed control volume has implications for the interpretation of our results, which we discuss further in section 4.2. By construction, the RVP is more general than SAMW. Because RVP is a fixed volume for any given experiment, it includes SAMW, along with some waters that are denser than SAMW. In the next section, we examine the sensitivity of the heat content of the RVP to net heat flux and wind stress.

\subsection{Adjoint Sensitivity Experiments}

In order to examine the sensitivity of RVPh to interior ocean properties and surface forcing, we perform a set of adjoint sensitivity experiments. The objective function is defined as the annual and volume mean RVP heat content:

$$
\tilde{J}=\frac{1}{V \Delta t} \int_{V} \int_{\Delta t} \rho_{0} c_{p} \theta(\mathbf{r}, t) d t d V
$$



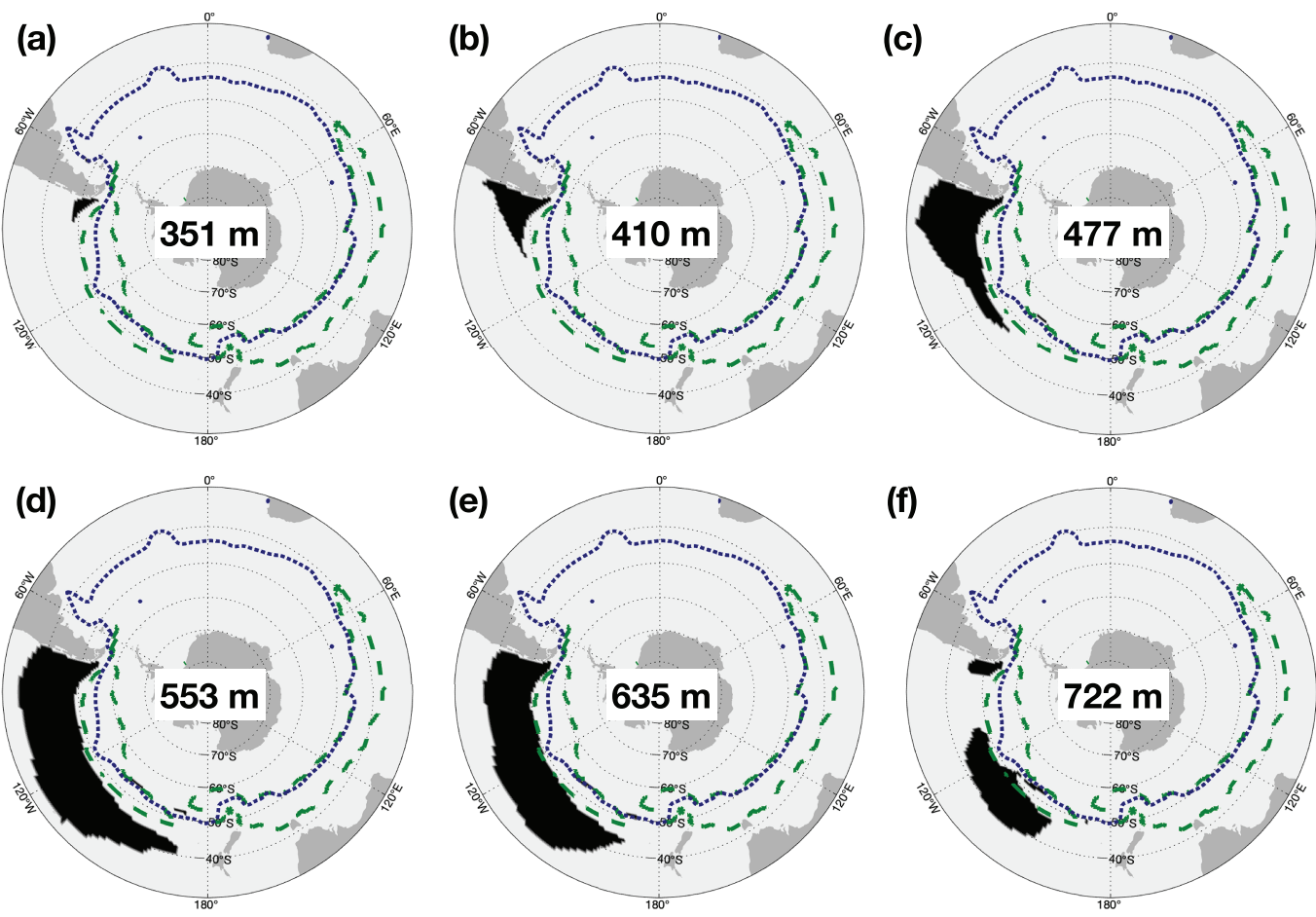

Figure 1. Tracer released in mode water formation regions ventilates the interior thermocline. Here we show the vertical structure of the ensemble median recently ventilated Pacific (RVP), which is used as the control volume in this study (black). For reference, we also plot the lateral extent of the tracer release sites (green dashed lines), and the 1992-2011 mean position of the $-0.25 \mathrm{~m}$ sea surface height contour, which is used as a proxy for the Subantarctic Front (blue dotted line) because it is the northernmost closed circumpolar contour. Depths indicate the depths of the grid cell centers.

where $\rho_{0}$ is the reference density, $c_{p}$ is the heat capacity of seawater, $\theta$ is the potential temperature, $\mathbf{r}$ is the position vector, $t$ is the time, $V$ is the control volume, and $\Delta t$ is the time period of the integration. For convenience, we scale $\tilde{J}$ by the constant $\rho_{0} c_{p}$, so RVPh $=J=\tilde{J} / \rho_{0} c_{p}$, meaning that RVPh has units of ${ }^{\circ} \mathrm{C}$.

We compute an ensemble of six 14-year adjoint sensitivity experiments, with the objective function defined over the last year of each run, that is, from 1 January to 31 December, with years ranging from 2006 to 2011. We allow the RVP to vary between experiments, which represents less than a $10 \%$ change in volume across the ensemble. Our ECCOv4 adjoint model calculates the sensitivities of these objective functions to a large set of independent variables, including temperature $(\partial J / \partial T)$, salinity $(\partial J / \partial S)$, net heat flux $(\partial J / \partial q)$, and wind stress $\left(\partial J / \partial \tau_{x}, \partial J / \partial \tau_{y}\right)$. We also calculated the sensitivities to evaporation minus precipitation minus runoff $(E-p-r)$, but we found the sensitivities, when scaled by 14-day forcing anomalies relative to the 1992-2011 average, to be negligibly small compared with the other fields. We do not consider $(E-p-r)$ further. We use 14-day averaged sensitivity fields throughout.

\section{Results}

We begin by examining the sensitivity of RVPh to net heat flux and wind stress forcing. We further examine the response mechanisms involved in the sensitivities to heat flux and wind stress using step response experiments.

\subsection{Sensitivity to Net Heat Flux}

We now examine the sensitivity of RVPh to surface forcing, starting with net heat flux. We use the convention that positive heat flux is out of the ocean; that is, positive flux tends to cool the surface ocean. The sensitivity fields calculated by the ECCOv4 setup are three-dimensional, as the sensitivity fields change with latitude, longitude, and time (Figure S2 and Movie S1). In order to estimate the eventual impacts of forcing anomalies on RVPh, we multiply the 14-day mean sensitivities by the corresponding 14-day mean surface forcing anomalies. The anomalies are calculated relative to the 20-year mean ECCOv4 state. As we only remove a 

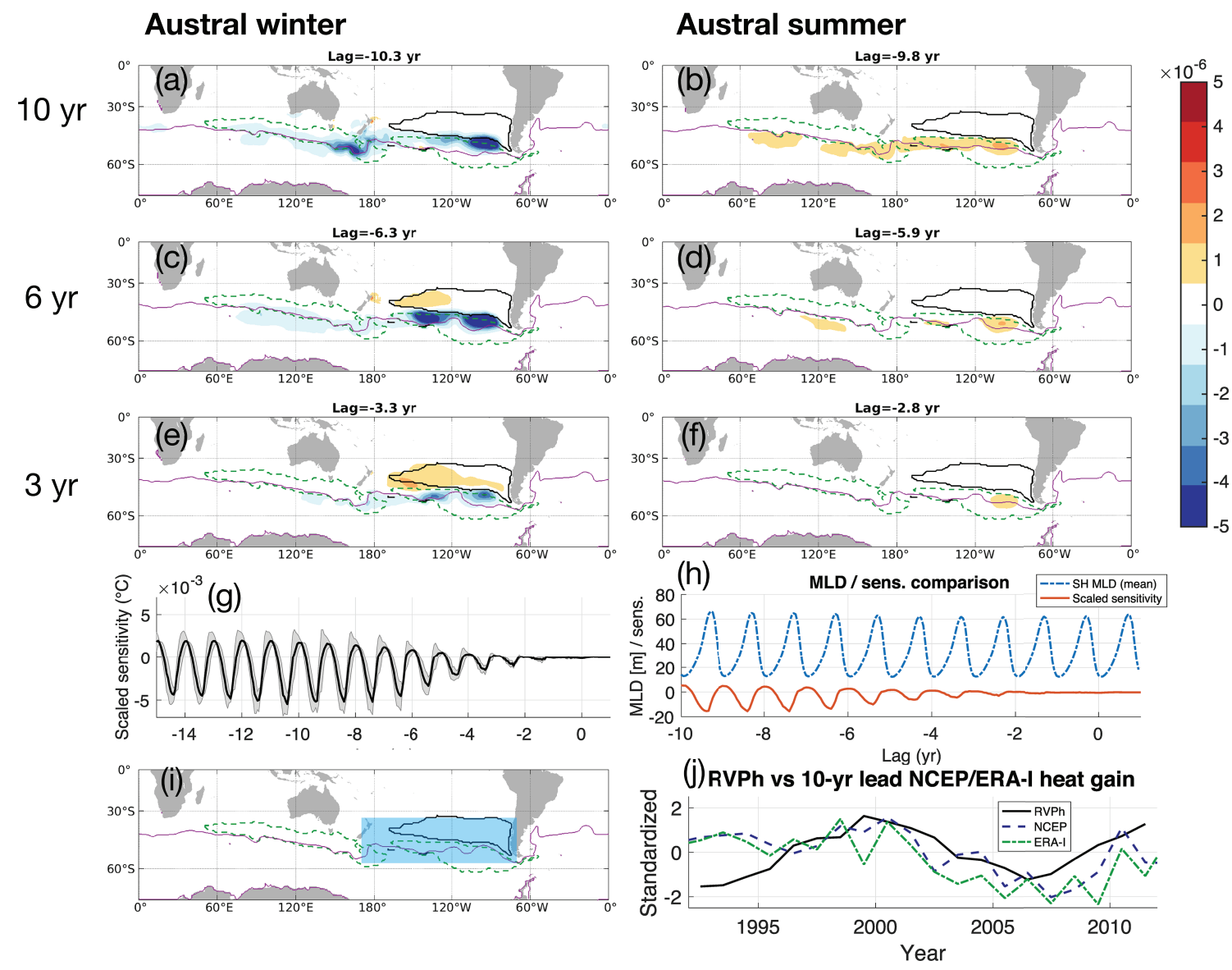

Figure 2. RVPh is most sensitive to wintertime heat flux anomalies, albeit with a multiyear lead time. (a-f) Ensemble mean sensitivity of fixed volume RVP heat content to net heat flux, multiplied by anomalies relative to annual mean climatology. At each grid cell, the eventual impact of the 14-day averaged forcing anomalies is shown in ${ }^{\circ} \mathrm{C}$. The seasonal cycle has not been removed from the anomalies. Positive/negative regions are associated with an eventual increase/decrease in annual mean RVPh, occurring after the indicated lag timescale has elapsed. For reference, we plot the 14-day mean SAF proxy (solid blue line), a cut through the RVP at roughly 553-m depth (black solid line), and a cut through the mixed layer mask at roughly 300-m depth (green dashed line). (g) Ensemble mean (solid line) and ensemble standard deviation (shading) scaled sensitivity, where Lag 0 marks the start of the target year. This time series summarizes sensitivity information from the entire global model domain. Here, scaled refers to the fact that the sensitivities have been multiplied by forcing anomalies. (h) Southern Hemisphere mean mixed layer depth (blue dot-dashed line) and sensitivity (red solid line, scaled arbitrarily for visibility). These time series summarize sensitivity and mixed layer depth information in the Southern Hemisphere and illustrate the relative phases of their variability. (i) Blue shading indicates the area over which NCEP and ERA-Interim heat gain is integrated, and (j) shows a standardized comparison of annual mean RVPh with 10-year lead heat gain from NCEP and ERA-Interim.

constant value at each grid cell, the forcing anomalies feature temporal variability on scales from 14-day to 20-year, including a seasonal cycle. Using this scaling, we can estimate the linear impacts of actual forcing anomalies on RVPh. For the unscaled sensitivity fields, see the supporting information. The linear change in $J$ expected from a forcing anomaly is

$$
\Delta J(\mathbf{r}, t)=\left[\frac{\partial J}{\partial x}(\mathbf{r}, t)\right][x(\mathbf{r}, t)-\bar{x}(\mathbf{r})],
$$

where $\bar{x}$ is the mean value of the forcing field over the ECCOv4-r2 period. Clearly, the sign of $\Delta J$ is determined by the product of the sign of the sensitivity field and the sign of the anomaly, such that positive and negative scaled sensitivities can potentially come from heat flux out of the ocean or heat flux into the ocean, depending on the sign of the sensitivity fields. The anomaly fields $x(\mathbf{r}, t)-\bar{x}(\mathbf{r})$ are averaged over 14-day periods in order to match the temporal averaging scale of the sensitivity fields.

The scaled sensitivities of RVPh to net heat flux indicate the eventual estimated change in RVPh induced by the net heat flux anomalies, as predicted by the adjoint sensitivities (Figure 2 and Movie S2). The sensitivities display a marked contrast between austral winter and austral summer. In austral winter, we find the largest scaled sensitivities just north of the South Antarctic Front (SAF) proxy, partially overlapping regions of 
deep mixed layers and the associated formation of SAMW. As the unscaled sensitivities are largely negative everywhere across all lags, the seasonal contrast in the sign of the scaled sensitivities comes from the sign of the net heat flux itself, with ocean heat loss in the austral winter and ocean heat gain in the austral summer. Regions of positive scaled sensitivity indicate a tendency for the actual net heat flux anomalies to increase RVPh, whereas regions of negative scaled sensitivity indicate a tendency for the actual net heat flux anomalies to decrease $\mathrm{RVPh}$. Unscaled sensitivities are shown in the supporting information.

At longer lags (e.g., Figure 2a), the scaled sensitivities extend throughout the Pacific basin to New Zealand, illustrating that the RVP is sensitive to anomalous heat fluxes in upstream regions, given sufficient time for those anomalies to propagate into the RVP. For shorter lags, (e.g., Figure 2e), the scaled sensitivities are more local. In austral summer, the scaled sensitivities are much smaller and tend to be positive, indicating a linear warming of the RVP; it is possible to warm the RVP by heating waters upstream of water formation regions. The austral winter sensitivity is stronger at 6 years than 10 years in the SE Pacific sector (Figures 2a-2c) while the austral summer sensitivity is strongest at 10 years. This may be indicative of a difference in the dominant processes between the two seasons, with summer solar forcing having a delayed impact on RVP properties compared to winter turbulent heat loss. We explore this idea further using heat flux perturbation experiments in section 3.2.

The globally integrated scaled sensitivity is negligibly small for sufficiently short lags, in part because the scaled sensitivity field features dipoles that partially cancel each other out, but mostly because the scaled sensitivities are weaker overall for short lags (Figure 2g). Relative to the target year, RVP heat content is more sensitive to heat flux from previous winters than from the most recent winter. For sufficiently long lags, the globally integrated scaled sensitivities show a clear seasonal cycle, in which the scaled sensitivities become more negative as the southern hemispheric $(\mathrm{SH})$ mixed layer deepens (Figure $2 \mathrm{~h}$ ). The scaled sensitivities lead the SH MLD by roughly 1.8 months $\left(R^{2}=0.81\right)$, which coincides with the period of strong mixing before the MLD reaches its deepest value. The ensemble standard deviation is relatively small (Figure S3); the largest standard deviations are located in regions where the sensitivities themselves are large, indicating that the sensitivity patterns are broadly coherent between ensemble members.

We have compared RVPh with integrated net heat flux anomalies over the broad region $\left(55-35^{\circ} \mathrm{S}, 170^{\circ} \mathrm{E}\right.$ to $70^{\circ} \mathrm{W}$ ) taken from the National Centers for Environmental Prediction/National Center for Atmospheric Research reanalysis and ERA-Interim reanalysis (Dee et al., 2011; Kalnay et al., 1996) (Figure 2j). The heat flux time series have been offset in the figure such that they leads RVPh by 10 years, and we observe a possible relationship between $\mathrm{RVPh}$ and heat flux anomalies over much of the period considered, indicating a decadal timescale for propagation of the anomalies into the RVP. Note the lack of agreement in the first 4 years of the time series may reflect uncertainties in the heat flux time series as National Centers for Environmental Prediction/National Center for Atmospheric Research and ERA-Interim are poorly constrained by observations prior to commencement of the satellite era in the mid-1980s (i.e., mid-1990s when lagged by 10 years).

\subsection{Heat Flux Perturbation Experiments}

In order to better understand the response of the RVP to net heat flux anomalies, we carried out four net heat flux perturbation experiments. We applied both positive and negative heat flux anomalies, with magnitude $50 \mathrm{~W} / \mathrm{m}^{2}$, over either June-July-August (JJA) or January-February-March (JFM), over a region of high linear sensitivities (Figure 3). As expected from the linear sensitivities, RVPh is more sensitive to perturbations in austral winter (JJA) than to perturbations in austral summer (JFM) (Figures $3 \mathrm{~b}$ and 3c). A positive heat flux anomaly (ocean heat loss) cools the RVP, and a negative heat flux anomaly (ocean heat gain) eventually warms the RVP, with a lag between forcing and response. For JJA perturbations, the maximum anomaly occurs roughly 3 years after the perturbation is applied, whereas the JJA response lacks a clear maximum.

This difference in timescale may reflect variations in the key processes involved. In summer, heat flux perturbations are likely dominated by solar forcing and confined to the near surface layer. The resulting temperature anomalies may not influence the RVP immediately the following winter if the winter mixing in the summer modified region is weak. Overall, summertime perturbations have little influence on RVP heat content. In winter, heat flux perturbations affect the RVP via both direct heat loss and by strengthening convection. The approximate 3-year lag is likely the combined result of the advection timescale into a region of strong mixing, the recurrence timescale for winters severe enough to produce mixing throughout the RVP, and the timescale of subduction and ventilation into the RVP. 


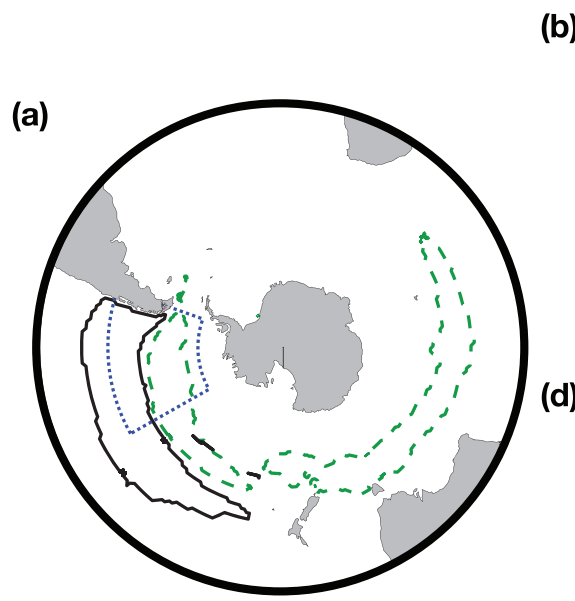

(b)

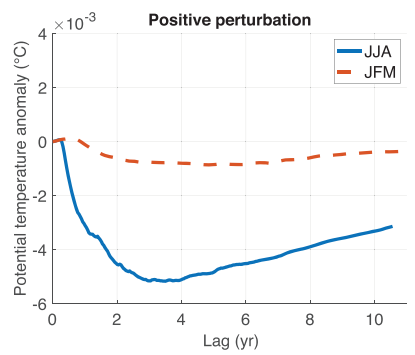

(d)

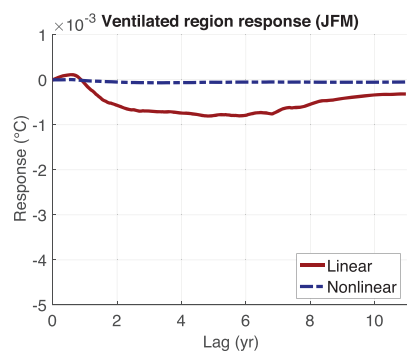

(c)

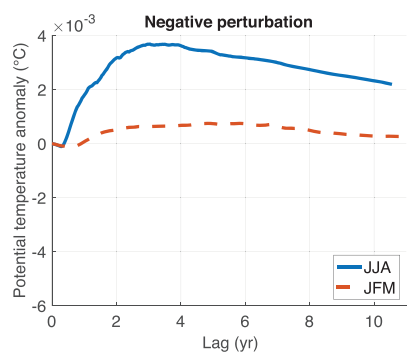

(e)

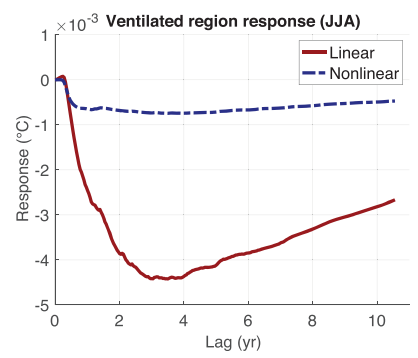

Figure 3. The results of nonlinear net heat flux experiments are broadly consistent with the predictions of the adjoint sensitivities. (a) Region of the imposed heat flux perturbations (blue dotted line), with the mixed layer mask (green dashed line) and ventilated region mask (black solid line) for reference.

(b) Response of the ventilated region to a positive net heat flux perturbation, corresponding to ocean heat loss, imposed in either June-July-August (solid blue line) or January-February-March (red dashed line). (c) Same as (b) but for a negative heat flux perturbation, corresponding to ocean heat gain. (d) The linear and nonlinear components of the ventilated region heat content for heat flux perturbations imposed over JFM. (e) Same as (d) except for heat flux perturbations imposed over JJA.

Adjoint models calculate the linear sensitivity of an objective function. We can decompose the response of RVPh into linear and nonlinear components (details in Appendix A). In the JFM case, the linear approximation is a good representation of the full nonlinear response; by magnitude, the maximum nonlinear response is roughly $8 \%$ of the maximum linear response. For the JJA perturbations, the linear approximation is also suitable, where the maximum magnitude nonlinear response is roughly $17 \%$ of the maximum magnitude linear response. The difference between the linear and nonlinear components may be a way to quantify the error in the adjoint approximation. The adjoint sensitivity fields cannot represent the tendency of heat fluxes to change mixing and convection via altering stratification. In this case, the error associated with this assumption is quantified by the difference between the linear and nonlinear responses (Figure 3). The quasi-linearity of the response indicates that the modulation of mixing by heat flux anomalies is not a major effect in terms of altering RVPh, especially considering that $50 \mathrm{~W} / \mathrm{m}^{2}$ is a large perturbation relative to climatological wintertime cooling.

\subsection{Sensitivity to Zonal Wind Stress}

The scaled sensitivities, which have been multiplied by zonal wind stress anomalies, represent the linear changes induced in RVPh by the 14-day averaged wind stress anomalies (Figure 4 and Movie S4). Overall, austral wintertime anomalies induce a larger linear change than austral summertime anomalies, reflecting the seasonal cycle in the wind stress forcing fields rather than the weaker seasonal cycle in the underlying unscaled sensitivity fields. The sensitivity fields feature a number of meridional dipoles, suggesting sensitivity to wind-driven convergence and divergence at the surface. Broadly speaking, the dipole patterns have stronger magnitudes in austral winter than in austral summer, which by contrast tends to feature mostly positive scaled sensitivities (Figure 4). At 10-year lag, the scaled sensitivity pattern extends as far west as the Agulhas current retroflection (south of South Africa) and as far south as roughly $60^{\circ} \mathrm{S}$, just south of the SAF proxy. The nonzero sensitivity values south of the SAF proxy are broadly consistent with Rintoul and England (2002), who find that Ekman transport across the SAF south of Australia can eventually impact the temperature properties of SAMW. Our sensitivity fields are also broadly consistent with Gao et al. (2018), who find wind stress curl between the SAF and the Polar Front can warm the SAMW. At shorter lags, the sensitivity field is increasingly local, suggesting that wind stress anomalies on timescales of 1-3 years and located south of the Antarctic Circumpolar Current (ACC) have a negligible impact on RVPh. 


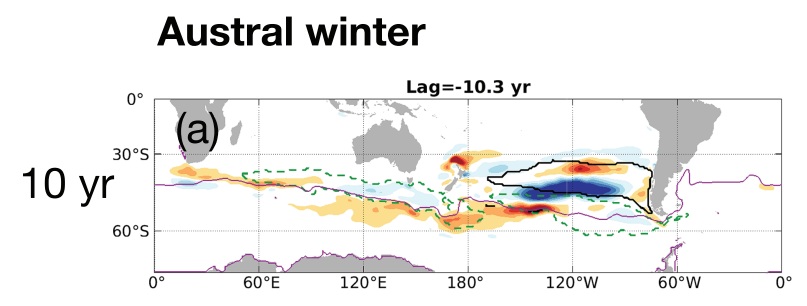

\section{Austral summer}
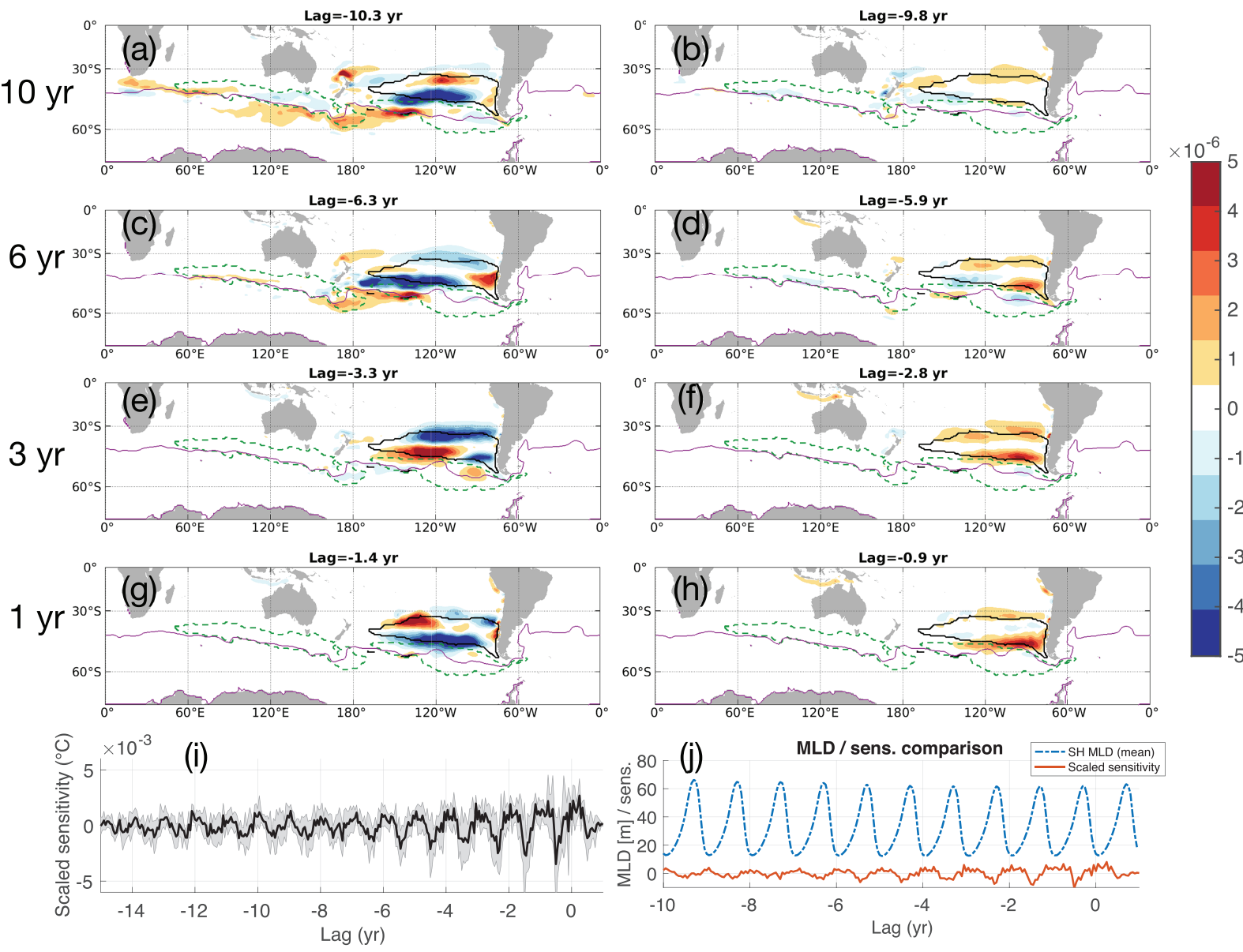

Figure 4. RVPh is most sensitive to local (in space and time) zonal wind stress anomalies, indicating the importance of gyre forcing. (a-h) Ensemble mean sensitivity of fixed volume RVP heat content to zonal wind stress, scaled by anomalies relative to annual mean climatology. At each grid cell, the eventual impact of the 14-day averaged forcing anomalies is shown in ${ }^{\circ} \mathrm{C}$. The seasonal cycle has not been removed from the anomalies. Positive/negative regions are associated with an eventual increase/decrease in annual mean RVPh, occurring after the indicated lag timescale has elapsed. We show a set of 14-day means at selected lags. For reference, we plot the 14-day mean SAF proxy (solid blue line), a cut through the objective function volume at roughly 553-m depth (black solid line), and a cut through the mixed layer mask at roughly 300-m depth (green dashed line). Units are in ${ }^{\circ} \mathrm{C}$. (i) Time series of ensemble mean (solid) and ensemble standard deviation (shading) scaled sensitivity. (j) Scaled comparison of Southern Hemispheric mixed layer depth and the sensitivity fields.

The globally integrated scaled sensitivity to zonal wind stress shows a strong seasonal cycle for relatively short lags, but at longer lags the seasonal cycle is harder to detect (Figure 4i). This is partly due to the presence of dipoles in the scaled sensitivity fields, which cancel out when added together. The integrated scaled sensitivity is roughly anticorrelated with SH MLD, with MLD leading sensitivity by less than one month $\left(R^{2}=0.36\right)$. The scaled sensitivity becomes more negative as the mixed layer deepens. The lag correlation between MLD and scaled sensitivity is periodic, with a period of approximately one year and little change in amplitude, indicating a strong correlation between the seasonal cycles of MLD and the scaled sensitivity.

The unscaled sensitivity to zonal wind stress $\left(\partial J / \partial \tau_{e}\right)$ features a persistent dipole pattern that spatially coincides with the RVP, with positive sensitivities in the southern part and negative sensitivities in the northern part (Figure S4 and Movie S3). If one were to perturb the zonal wind stress using a pattern with the same sign and spatial distribution as the sensitivities, one would induce gyre-scale Ekman convergence and Ekman pumping, thereby pushing isopycnal surfaces associated with the subtropical gyre downward. The resulting combination of isopycnal heave and the spinup of the subtropical gyre would increase RVPh. The ensemble standard deviation is small and centered on the Southeast Pacific (Figure S5). 


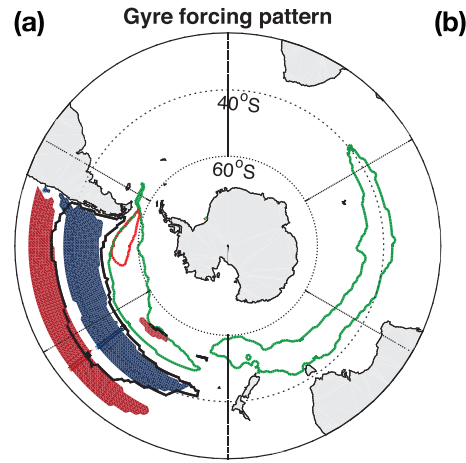

(b)

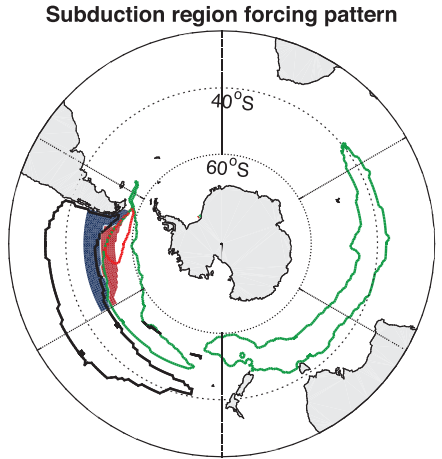

(c)

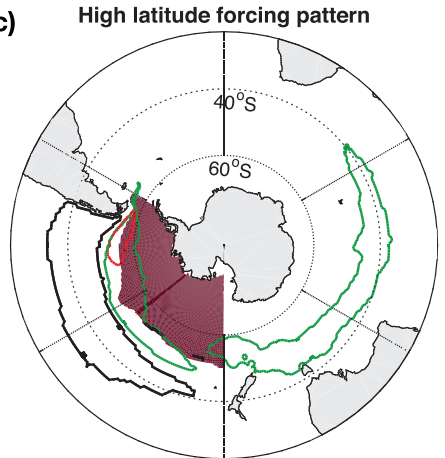

Figure 5. We used the adjoint sensitivity fields to design three nonlinear step response experiment types with respect to zonal wind stress, namely (a) gyre forcing, (b) forcing over the subduction region, and (c) high-latitude forcing. Positive (red) regions indicate eastward wind stress, and negative (blue) regions indicate westward wind stress. This plot shows the perturbations that are referred to as positive. Shown for reference is the mixed layer mask (green), the ventilated region mask (black), and a $600 \mathrm{~m}$ maximum mixed layer contour (red). The perturbation fields referred to as "negative" have the opposite signs of those shown.

\subsection{Zonal Wind Stress Step Response Experiments}

The scaled sensitivity fields suggest that, on the 0 - to 15-year timescales considered in this work, $\mathrm{RVPh}$ is most sensitive to local wind stress anomalies, specifically those that spatially coincide with the latitude-longitude range of the RVP and with the eastern portion of the South Pacific subpolar gyre. The RVP is also sensitive to wind stress anomalies in the mode water formation and subduction region found in the eastern Pacific. Furthermore, on timescales longer than 5-6 years, the RVP is also sensitive to wind stress anomalies south of the SAF proxy. In order to examine the adjustment of the RVP to anomalies in these three broad regions, we performed three pairs of wind stress step response experiments, using three different spatial patterns and signs that either match the sensitivity fields (called the "positive" experiments) or oppose them (called the "negative" experiments, in that they have been multiplied by -1) (Figure 5). All step changes have the same magnitude of $0.020 \mathrm{~N} / \mathrm{m}^{2}$, which is roughly $22 \%$ of the 1992-2011 mean
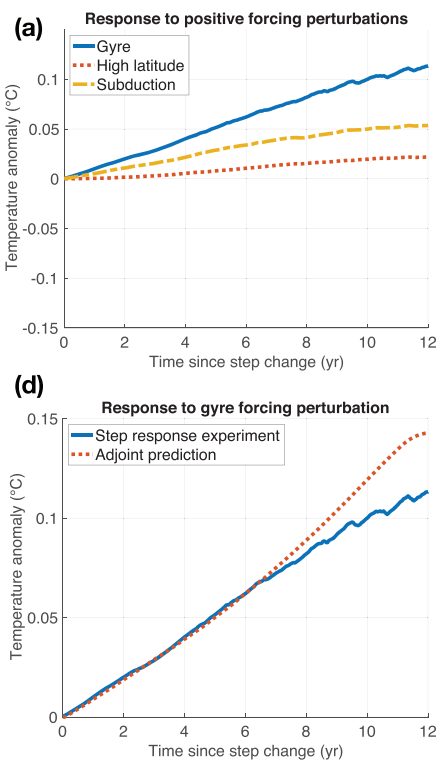

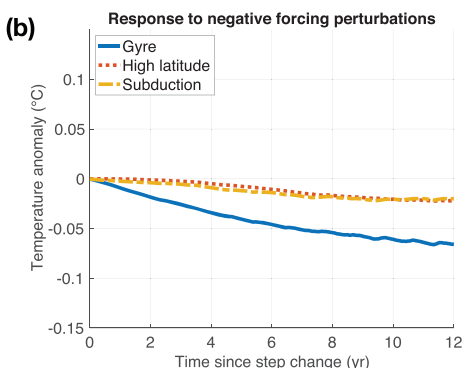

(e)

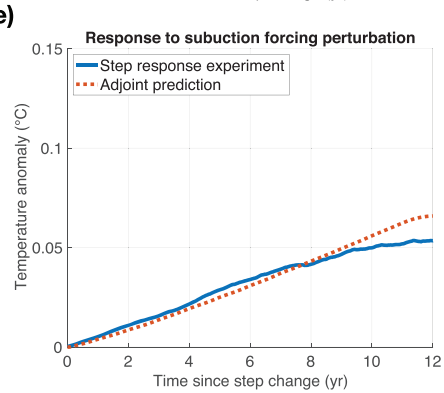

(c)

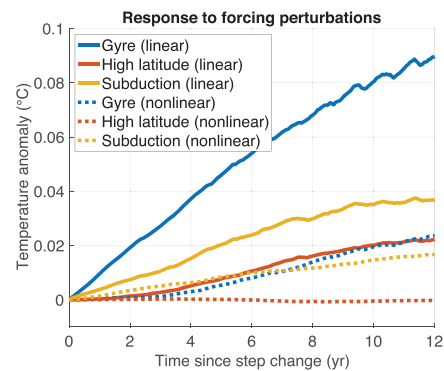

(f)

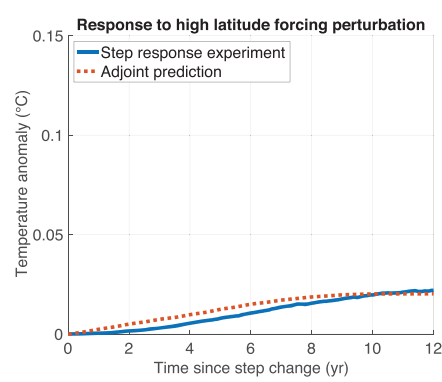

Figure 6. The results of the nonlinear step response experiments are broadly consistent with the adjoint predictions; the gyre forcing pattern produces the strongest response in general. Shown are the responses of RVPh defined in the text to (a) the positive forcing patterns and (b) the negative forcing patterns. All three experiment types are shown; gyre (blue solid lines), high latitude (red dotted lines), and subduction (green dash-dotted lines). (c) The linear (solid lines) and nonlinear (dotted lines) responses to the three different forcing patterns. Also shown are comparisons between the results of the step response experiment and the change predicted by convolving the adjoint sensitivity fields with the imposed change in wind stress for the (d) gyre, (e) subduction, and (f) high-latitude forcing patterns. 

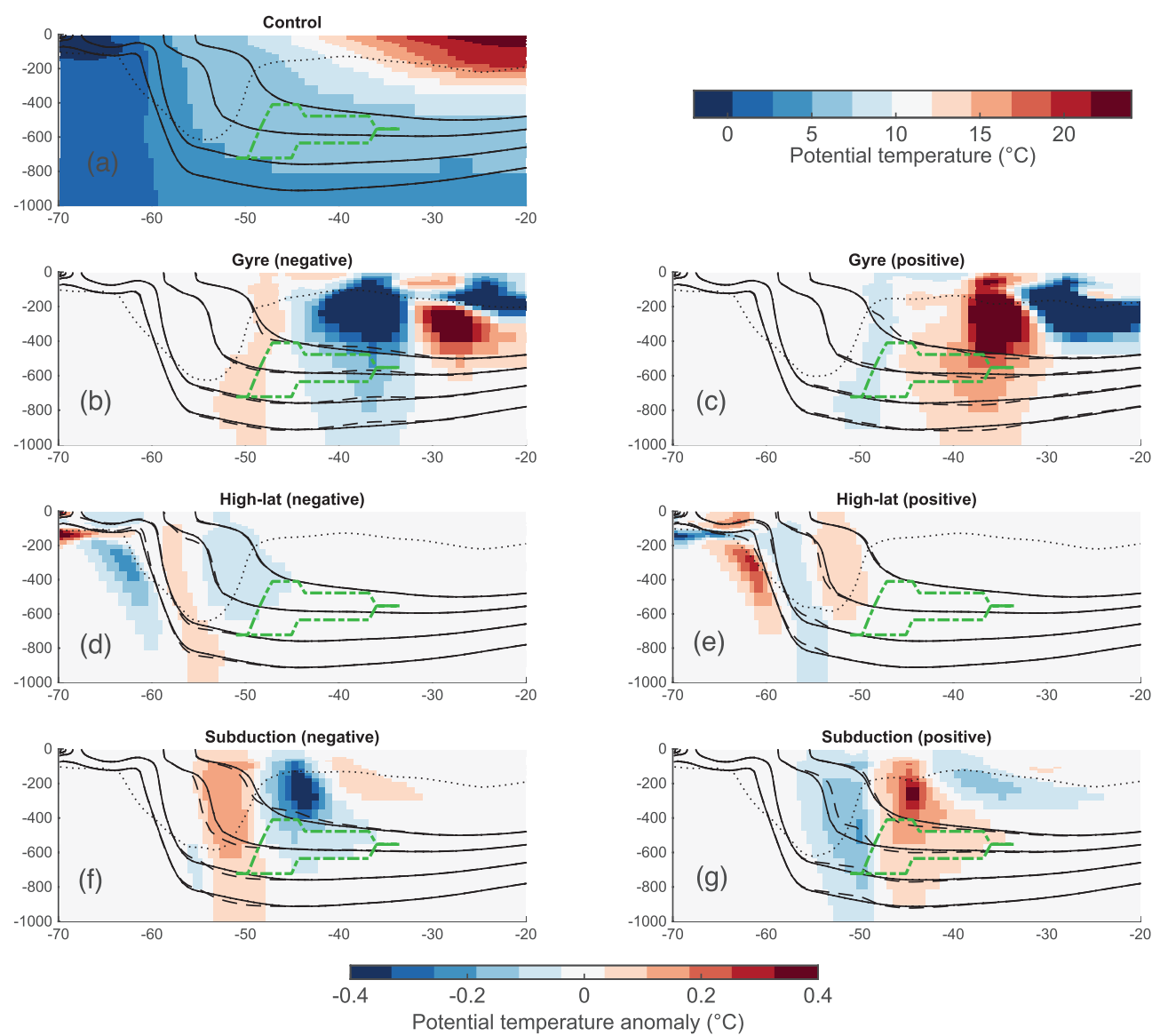

Figure 7. Each wind stress step response experiment type has a characteristic "fingerprint" in terms of temperature anomalies; the anomaly pattern induced by gyre forcing has the strongest and most immediate impact on RVPh. Shown are the responses of potential temperature and density to step changes in wind stress, shown as annual mean potential temperature anomaly sections at $100^{\circ} \mathrm{W}$, relative to the control run [shown in panel (a)], 10 years after the step change in zonal wind stress. In each panel, we plot a cut through the (fixed volume) RVP used in the adjoint sensitivity experiments (green dash-dot line), the maximum mixed layer depth (black dotted line), annual mean potential density surfaces (indicating $26.9 \sigma_{0}$ to $27.2 \sigma_{0}$, in $0.1-\mathrm{kg} / \mathrm{m}^{3}$ increments) for the control run (solid black lines) and the step response experiments (dashed black lines). We plot anomalies for the gyre forcing pattern $(b, c)$, the high-latitude forcing pattern (d, e), and the subducted region forcing pattern (f, g).

zonal wind stress between $30^{\circ} \mathrm{S}$ and $70^{\circ} \mathrm{S}\left(0.090 \mathrm{~N} / \mathrm{m}^{2}\right)$ and roughly $80 \%$ of the standard deviation averaged over the same latitudes $\left(0.025 \mathrm{~N} / \mathrm{m}^{2}\right)$. All perturbations start in model year 1996; we chose this year as the stratification before 1996 is anomalously weak relative to the 1992-2011 mean.

The "gyre" forcing pattern (Figure 5a) is derived from the unscaled sensitivities (Figure S4). This pattern represents the influence of wind stress curl on spinning up or spinning down the gyre, with the associated shifts on isopycnal depths. Based on the unscaled sensitivities, uniform perturbations in this area are expected to have the largest impact on RVP heat content than any other region. The "subduction" forcing pattern (Figure 5b) is over a region where there are deep mixed layers which is also part of the ventilated region-changes in wind forcing here may affect the rate of water mass subduction into the ocean interior. Based on the unscaled sensitivities, uniform perturbations in this area will have a smaller but nonzero effect on the heat content of the RVP. Finally, the "high-latitude" forcing pattern (Figure 5c) is south of the SAF proxy, that is, in a region largely dominated by circumpolar flow. Wind stress changes here can affect the high-latitude upwelling which forms a crucial part of the overturning circulation. Based on the unscaled sensitivities, this region is expected to have a relatively small effect on the heat content of the RVP.

The impacts of the step changes in wind stress agree well with the impacts suggested by the scaled sensitivity fields (Figure 6). In response to the positive gyre step change, the RVP warms roughly linearly at a rate of 
$0.09{ }^{\circ} \mathrm{C}$ per decade. In response to the positive subduction region step change, the RVP warms roughly linearly at a rate of $0.04{ }^{\circ} \mathrm{C}$ per decade, and in response to the high-latitude change, the RVP warmed at a rate of $0.02{ }^{\circ} \mathrm{C}$ per decade. In response to the negative perturbations, the RVP cools in all three cases (Figure $6 \mathrm{~b}$ ). For the gyre and subduction forcing cases, the magnitude of cooling is smaller than the magnitude of warming in the corresponding positive forcing experiments, at least partly due to nonlinear responses in the isopycnal tilt within the RVP. The magnitude of cooling induced by the high-latitude pattern is nearly identical to the magnitude of warming in the corresponding positive forcing experiment; this forcing pattern does not substantially move the isopycnals within the RVP. For all three patterns, the responses are largely linear across all timescales considered here (0-12 years) (Figure 6c). After 12 years, the response to the gyre pattern is $79 \%$ linear, the response to the high-latitude pattern is $99 \%$ linear, and the response to the subduction pattern is $69 \%$ linear. The warming induced by the positive step changes roughly match those predicted by the adjoint sensitivities, calculated by convolving the unscaled adjoint sensitivity fields with the imposed step change patterns (Figures 6d-6f). The differences between the responses in the nonlinear forward experiment and the responses predicted by the linear adjoint sensitivity fields highlight differences between the forward and adjoint model, specifically the absence of nonlinear processes in the adjoint.

Although the imposed changes in wind stress are relatively simple, the responses that they induce can be complex. In order to analyze the response mechanisms excited by the imposed step changes in wind stress, we examine sections of annual mean temperature anomalies in the far eastern South Pacific (Figure 7). Note that the temperature anomalies are much larger near the surface above the RVP region and extend downward into the RVP, especially for the gyre forcing case. The anomalies vary with longitude as well (Figure S6). The negative gyre forcing induces Ekman suction (upwelling) centered at roughly $37^{\circ} \mathrm{S}$ and the associated shoaling of interior isopycnals, bringing relatively cold water from below into the fixed volume RVP, thereby reducing the RVPh as seen in Figure $6 \mathrm{~b}$. The negative gyre forcing also induces warming at lower latitudes, but this does not directly affect RVPh. The oppositely signed positive gyre forcing mostly induces the opposite pattern, that is, Ekman pumping, downwelling between $30^{\circ} \mathrm{S}$ and $40^{\circ} \mathrm{S}$, and deepening of isopycnals that moves relatively warm water into the fixed volume RVP.

The high-latitude forcing perturbation has only a weak impact on the positions of the isopycnals that cut through the RVP, instead inducing changes in the water that subducts into the RVP. The negative perturbation moves cold, high-latitude water northward across the ACC via Ekman transport, where cold anomalies can then be subducted below the mixed layer and into the RVP. The positive perturbation induces the opposite response, with poleward Ekman transport anomalies leading to an anomalously warm RVP.

The subduction forcing perturbation changes high-latitude wind stress curl and the associated Ekman suction/pumping, which leads to shoaling/deepening of isopycnals between $40^{\circ} \mathrm{S}$ and $50^{\circ} \mathrm{S}$ and cooling/warming of the RVP. The perturbation also induces warming/cooling of the water that subducts into the RVP that resembles a combination of the patterns induced by the high-latitude change and gyre change, albeit on deeper isopycnals. The responses within the RVP due to Ekman changes and the responses in the RVP source waters have opposite signs, so the net effect depends on the balance between isopycnal heave and changes in properties of the subducted water.

\subsection{Sensitivity to Northward Wind Stress}

The meridional wind stress sensitivity fields indicate that the RVP is sensitive to wind stress along the west coast of South America and, on timescales longer than 4-5 years, to wind stress along the west coast of New Zealand in winter (Figure 8 and Movie S6). The sign changes in the scaled sensitivities come largely from the forcing anomalies, as the signs of the unscaled sensitivities are relatively constant (Figure S7 and Movie S5). Northward wind stress parallel to the western coast of Chile induces Ekman transport away from the coast, creating cross-shelf pressure gradients and anomalous upwelling. Southward wind stress has the opposite effect, ultimately suppressing coastal upwelling. The unscaled sensitivity fields show consistently positive sensitivities along much of the Chilean coast, with negative along-coast sensitivities to the north, and positive offshore sensitivities (Figure S4). The unscaled sensitivities do not change significantly with season, but the scaled sensitivities, which have been convolved with northward wind stress anomalies, show a seasonal cycle. The scaled sensitivities along the Chilean coast are negative in austral winter and positive in austral summer. In combination with the unscaled sensitivity fields, this indicates that in winter, southward meridional wind stress anomalies suppress coastal upwelling, linked with a drop in RVPh, and in summer 
Austral winter
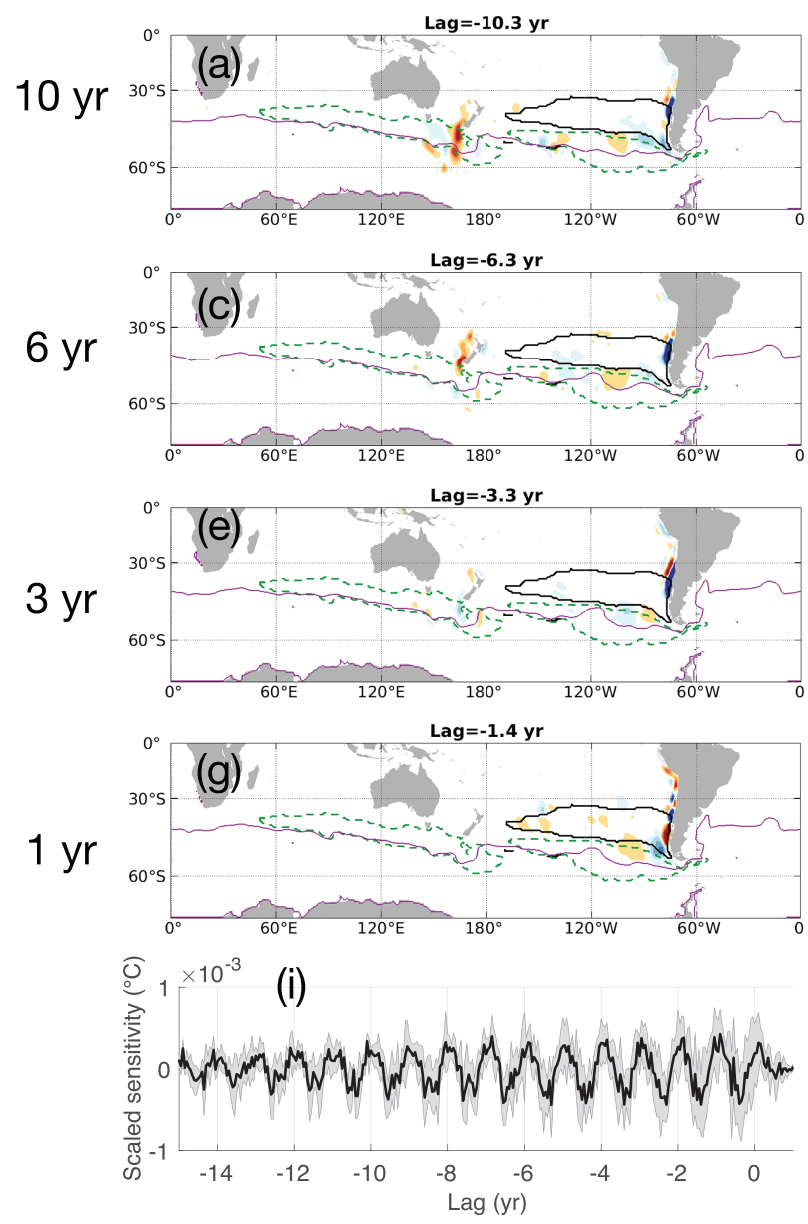

Austral summer
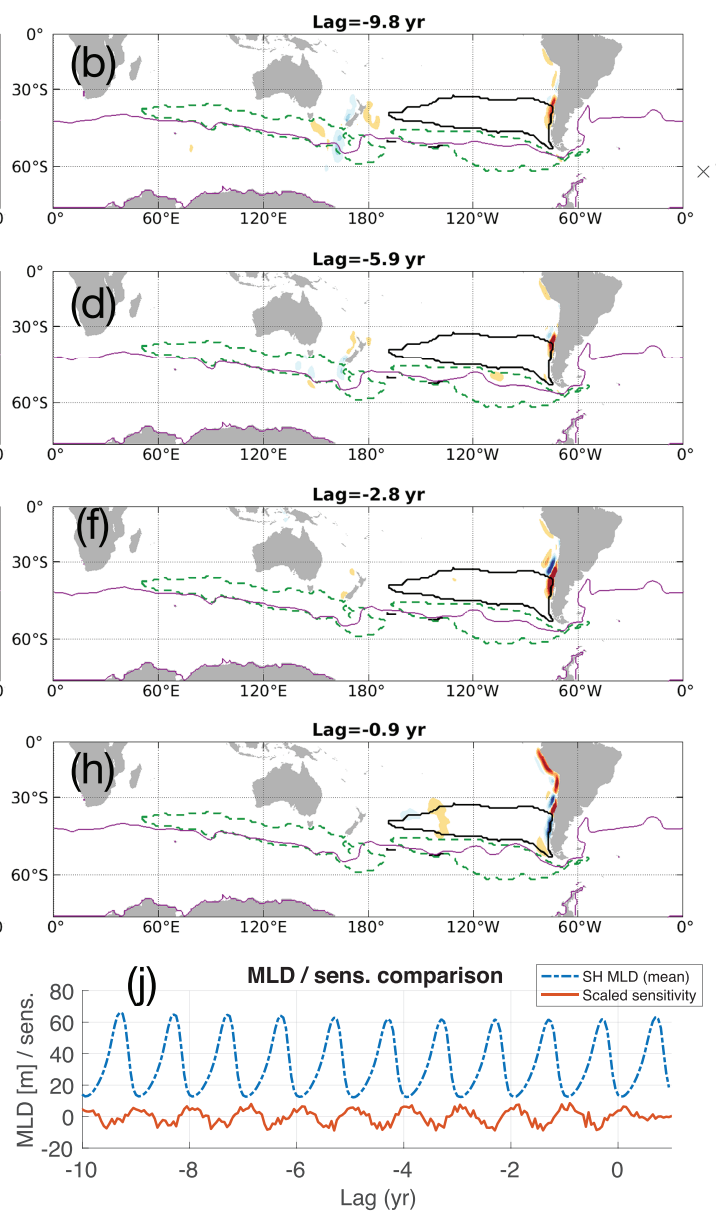

Figure 8. RVPh is most sensitive to meridional wind stress anomalies along the western coast of South America and (after a lag of several years) New Zealand, in part reflecting their role in setting basin-scale pressure gradients. $(\mathrm{a}-\mathrm{h})$ Ensemble mean sensitivities of fixed volume RVP heat content to meridional wind stress, scaled by anomalies relative to annual mean climatology. At each grid cell, the eventual impact of the 14-day averaged forcing anomalies is shown in ${ }^{\circ} \mathrm{C}$. The seasonal cycle has not been removed from the anomalies. Positive/negative regions are associated with an eventual increase/decrease in annual mean $\mathrm{RVPh}$, occurring after the indicated lag timescale has elapsed. For reference, we plot the 14-day mean SAF proxy (solid blue line), a cut through the objective function volume at roughly 553-m depth (black solid line), and a cut through the mixed layer mask at roughly 300-m depth (green dashed line). (i) Time series of ensemble mean (solid) and ensemble standard deviation (shading) scaled sensitivity. (j) Scaled Southern Hemisphere mixed layer depth and sensitivity fields show some seasonality and a correspondence between the two time series.

northward anomalies increase upwelling, linked with a rise in RVPh. The mechanisms are investigated in the perturbation experiments in section 3.6.

The globally integrated scaled sensitivity shows a seasonal cycle in both the ensemble mean and standard deviation (Figure 8i). Southern Hemisphere MLD leads the scaled sensitivity by roughly 1 month $\left(R^{2}=0.49\right)$. The scaled sensitivity gets more negative as the mixed layer deepens, and the scaled sensitivity gets more positive as the mixed layer shoals [Figure 8j]. The lag correlation between the meridional wind stress and the mixed layer is periodic, with a period of approximately 1 year and little change in magnitude, indicating a persistent correlation between the seasonal cycles of both quantities. The overall magnitude of the scaled sensitivity is weaker than that of zonal wind stress, in part due to the smaller area occupied by the meridional sensitivity fields.

\subsection{Meridional Wind Stress Step Response Experiments}

To investigate adjustment mechanisms highlighted by the scaled sensitivities, we performed a pair of meridional wind stress step response experiments. We imposed the step change along the western coast of Chile (Figure 9a), either northward or southward with a magnitude of $0.02 \mathrm{~N} / \mathrm{m}^{2}$. This is a relatively large perturbation compared with the mean meridional wind stress (magnitude $0.008 \mathrm{~N} / \mathrm{m}^{2}$ ) and larger than the spatial 

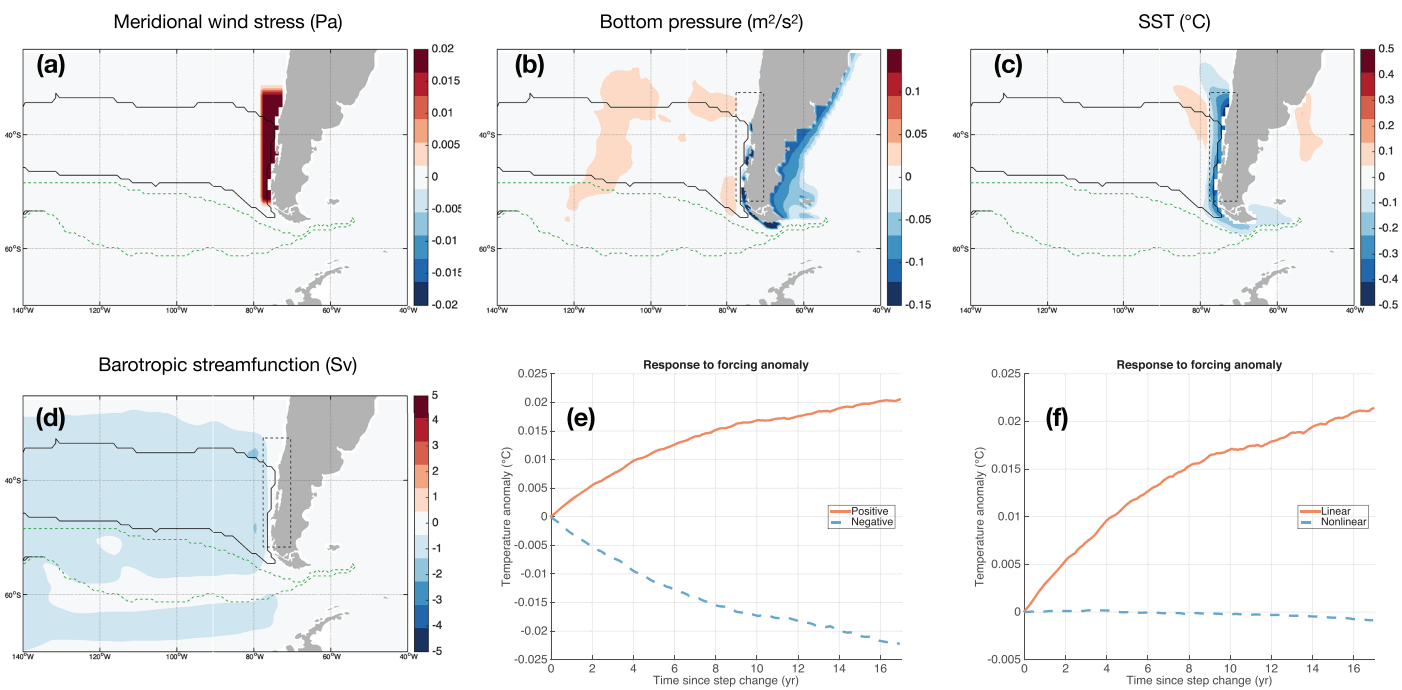

Figure 9. Nonlinear step response experiments illustrate how meridional wind stress anomalies can affect pressure gradients and barotropic circulation, with implications for RVPh. (a) Imposed meridional wind stress perturbation, along with mixed layer mask (green dashed line) and the RVP mask (black solid line) for reference. Annual mean anomalies for the (b) bottom pressure, (c) sea surface temperature, and (d) barotropic streamfunction are shown, 10 years after the imposed wind stress anomaly. Also shown is the time series of (e) the RVPh response to positive and negative imposed anomalies and (f) the linear and nonlinear components of this response.

mean standard deviation $\left(0.01 \mathrm{~N} / \mathrm{m}^{2}\right)$, calculated between $60-80^{\circ} \mathrm{W}$ and $30-70^{\circ} \mathrm{S}$. The northward wind stress anomaly induces Ekman transport away from the coast, creating a negative pressure anomaly that rapidly propagates around the southern tip of South America (Figure 9b). The associated coastal upwelling brings cooler waters up to the surface, creating negative sea surface temperature anomalies (Figure 9c). The change in pressure eventually changes the barotropic circulation identified with the subtropical gyre and the ACC. The resulting change in circulation alters the heat convergence into the RVP and induces warming (Figure 9e). The negative step response experiment produces the opposite response; indeed, the response of the RVP to this set of step response experiments is almost entirely linear (Figure 9f).

\subsection{Comparing Scaled Sensitivities Net Heat Flux and Wind Stress}

For lags shorter than 3-5 years, RVPh is most sensitive to globally integrated wind stress anomalies relative to annual mean climatology, and for longer lags, RVPh is most sensitive to globally integrated net heat flux
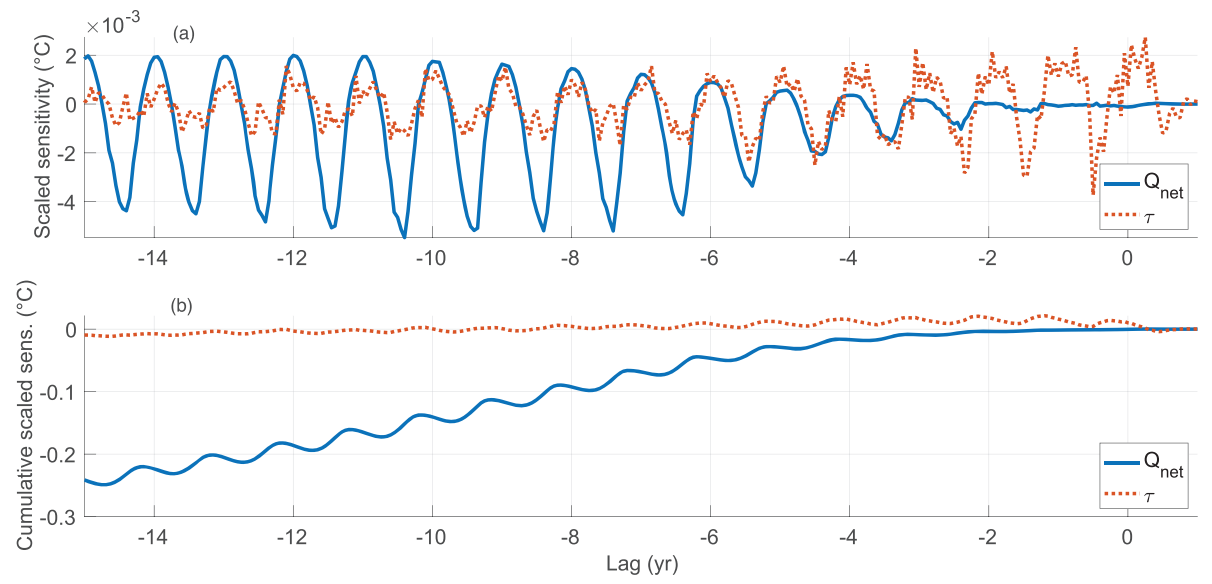

Figure 10. Relative scaled sensitivities show that wind stress anomalies dominate (in terms of magnitude) RVPh on timescales shorter than 3-5 years, while net heat flux anomalies dominate on timescales longer than 3-5 years. Time series of (top) scaled sensitivity and (bottom) cumulative scaled sensitivity. Here we combine the linear impacts of zonal wind stress and meridional wind stress into a single "wind stress" measure. 
(a)

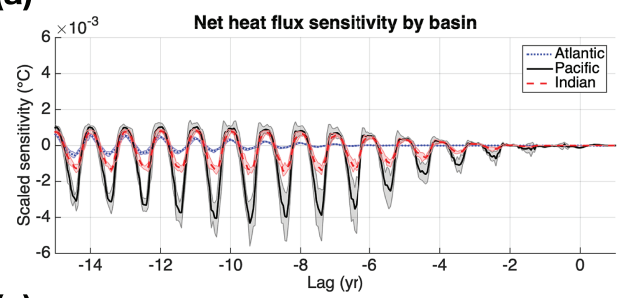

(c)

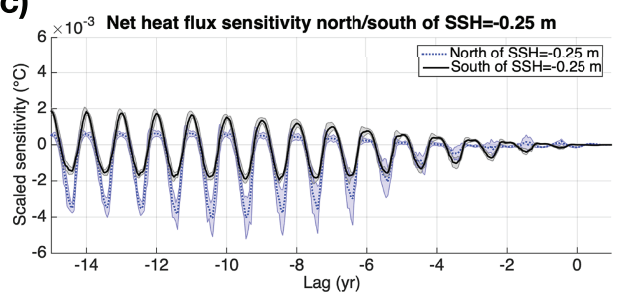

(b)

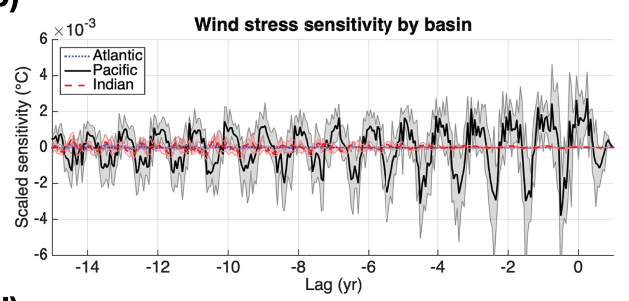

(d)

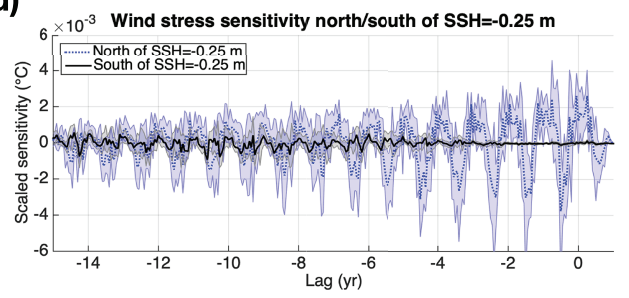

Figure 11. RVPh sensitivity to net heat flux is dominated by heat flux anomalies in the Pacific basin north of the SAF proxy (in terms of the magnitude of the sensitivities); RVPh sensitivity to wind stress is also dominated by anomalies in the Pacific basin north of the SAF proxy. Shown are scaled sensitivity time series for net heat flux and wind stress, decomposed by $(\mathrm{a}, \mathrm{b})$ ocean basin and (c, d) position north or south of the SAF proxy. Zonal and meridional wind stresses have been combined into a single wind stress measure.

anomalies [Figure 10a]. Wind stress anomalies can directly alter RVPh by inducing wind stress curl anomalies over the RVP, which drives isopycnal heave. Net heat flux anomalies take longer to affect RVPh because these anomalies must ultimately propagate from the surface into the RVP following subduction pathways. Both scaled sensitivity time series feature a strong seasonal cycle, indicating a coupling with mixed layer dynamics as discussed in previous sections.

The cumulative effects of surface forcing anomalies on RVPh are estimated as follows:

$$
d J_{\text {cumulative }, x}(t)=\int_{A} \int_{t^{\prime}=t}^{1 y e a r} \Delta J\left(\mathbf{r}, t^{\prime}\right) d t^{\prime} d A=\int_{A} \int_{t^{\prime}=t}^{1 \text { year }}\left[\frac{\partial J}{\partial x}(\mathbf{r}, t)\right][x(\mathbf{r}, t)-\bar{x}(\mathbf{r})] d t^{\prime} d A,
$$

where $x$ is one of the surface forcing variables (i.e., net heat flux, zonal wind stress, and meridional wind stress). We integrate over the global ocean area $A$, from time $t$ throughout the entire target year (to $t^{\prime}=$ 1 year). The cumulative impact of wind stress anomalies is ultimately close to 0 , as the warming and cooling impacts roughly cancel out on sufficiently long timescales, leaving only a small residual [Figure 10b]. Reading the figure from right to left, the cumulative effect of net heat flux perturbations is a long-term cooling, reflecting the collective action of anomalies over an increasing fraction of ocean surface area with time and also the predominance of wintertime heat flux anomalies. By comparison, wind stress terms roughly cancel out when averaged over a seasonal cycle.

RVPh is most sensitive to surface forcing anomalies (relative to annual mean climatology) integrated over the Pacific basin [Figures 11a and 11b]. This is not surprising, as the RVP is situated in the relatively isolated far eastern Pacific Ocean. Note the asymmetry about zero in the Pacific time series (Figure 11a, which explains a large fraction of the asymmetry about zero in Figure 10. Net heat flux anomalies in the Indian basin make a significant contribution as well, largely driven by anomalies south of Australia and New Zealand. Wind stress sensitivity is especially dominated by anomalies in the Pacific basin, mostly reflecting the impact of the local wind stress curl. We find that RVPh is most sensitive to surface forcing anomalies north of the SAF proxy [Figures 11c and 11d], although heat flux anomalies south of the SAF proxy do increase with lag. Overall, surface forcing anomalies in regions south of the SAF proxy do not have a strong impact on the fixed volume RVPh.

\section{Discussion of Interannual Variability, Changes in the Ventilated Volume, and Limitations}

Regional variations in surface forcing across a wide range of timescales can ultimately impact the SO subduction and ventilation process, which forms a critical part of the meridional overturning circulation (MOC) (Marshall and Speer, 2012). The transport of heat and carbon by the MOC critically affects the partition of 

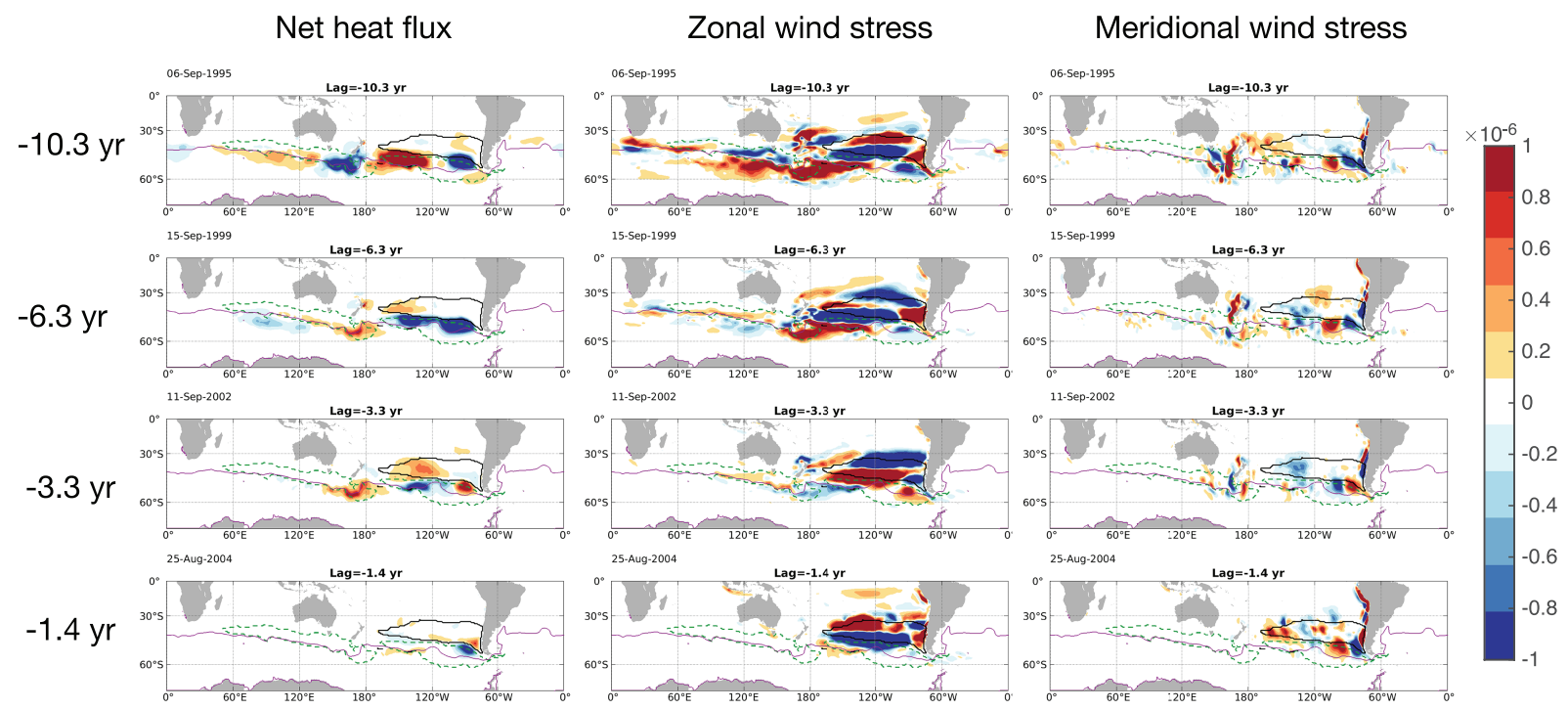

Figure 12. Removing the seasonal cycle from the forcing anomalies changes the details of the scaled sensitivity patterns, but it does not alter our major conclusions. Ensemble mean sensitivity of fixed volume RVP heat content to surface forcing components, scaled by anomalies relative to monthly mean climatology (i.e., monthly mean values have been subtracted from the forcing fields). At each grid cell, the eventual impact of the 14-day averaged forcing anomalies is shown in ${ }^{\circ} \mathrm{C}$. Positive/negative regions are associated with an eventual increase/decrease in annual mean RVPh, occurring after the indicated lag timescale has elapsed. Each plot shows a 14-day mean taken sometime in August-September, that is, austral winter. Note that the color scale is different than for previous scaled sensitivity plots.

heat and carbon between the ocean and the atmosphere, regulating the rate of anthropogenic surface warming. We used a suite of adjoint sensitivity experiments to highlight the specific locations and timescales on which ocean properties, net heat flux, and wind stress can affect the heat content of the recently ventilated interior. We focused our attention on an especially efficient export pathway, which carries weakly stratified water from the surface into the interior Pacific. An extension of this work into multiple basins would be a welcome addition to this study.

\subsection{Interannual Variability in Surface Forcing}

In order to highlight the locations and timescales where interannual surface forcing most contributes to variability in annual mean RVPh, we present an alternative set of scaled sensitivities that have been convolved with monthly mean forcing anomalies, highlighting departures from the ECCO seasonal cycle:

$$
\Delta J(\mathbf{r}, t)=\left[\frac{\partial J}{\partial x}(\mathbf{r}, t)\right][x(\mathbf{r}, t)-\bar{x}(\mathbf{r}, t)],
$$

where $\bar{x}$ is the monthly mean climatology of the forcing field over 1992-2011. First and foremost, the magnitudes are reduced as one would expect since the relatively large and persistent seasonal signal has been omitted. The overall spatial patterns of sensitivity are similar to those derived using anomalies from annual mean climatology, with some notable differences (Figure 12). In the Pacific sector, RVPh is most affected by net heat flux anomalies south of the RVP projection and north of the SAF proxy, which lies within a region of deep mixed layers, and in the Indian sector, we find regions of sensitivity south of the SAF proxy. The locations of these sensitivities are consistent with those from annual mean climatology (Figure 2) and with the unscaled sensitivity (see the supporting information), but the sign structure is more complex, reflecting departures from monthly mean forcing values. We find similar results with both zonal and meridional wind stress. The globally integrated sensitivity values are much smaller than in the climatological case, reflecting the increased presence of sensitivity dipoles that cancel out during integration (Figure S8).

\subsection{Changes in the Ventilated Volume}

We found that on timescales shorter than roughly 4-6 years, RVPh is strongly affected by wind stress anomalies above the SPG. Wind stress curl anomalies over the SPG affect Ekman convergence/divergence and the associated Ekman pumping/suction that drives isopycnal heave. The relative dominance of the SPG in setting RVPh on these timescales may seem at odds with the canonical view of the MOC in the SO (Marshall and Speer, 2012). In this view, Circumpolar Deep Water is upwelled south of the ACC as part of the residual overturning circulation and exported northward at the surface, getting modified by surface fluxes, and 


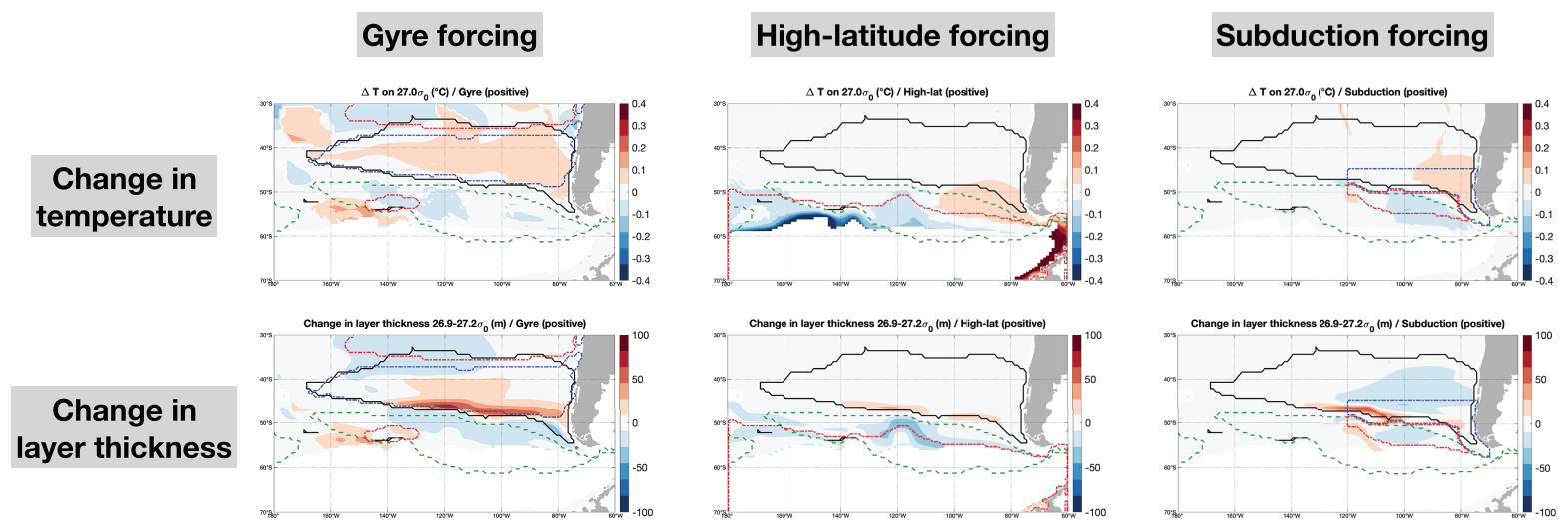

Figure 13. Each zonal wind stress forcing pattern changes both along-isopycnal properties and isopycnal layer thickness, both of which can affect the total heat stored in the thermocline. Although RVPh cannot capture sensitivities to changes in layer thickness, this limitation does not change our major conclusions. Shown are annual mean changes in temperature on density levels $(a-c)$ and changes in layer thickness $(\mathrm{d}-\mathrm{f}), 10$ years after the imposed step changes in wind stress. Blue and red contours show regions where the wind stress changes are imposed, with positive changes shown in red and negative changes shown in blue. The green dashed line is the MLD mask used in the tracer experiments.

ultimately being subducted as SAMW and Antarctic Intermediate Water (AAIW) where it spreads along isopycnals into the subtropical gyres. Changes in the properties of this subducted volume are then thought to be more sensitive to changes in the subducted water masses and their southern sources Naveira Garabato et al. (2009, e.g.), Cerovecki et al. (2019), and thus, it is surprising to see the weak sensitivity fields over the ACC relative to the subtropical gyre. The difference can be understood due to the fixed volume nature of the RVP as defined in the adjoint model. Here we must use a fixed volume based on the model setup, which captures the mean position of the ventilated water but does not move with the isopycnals as they heave. By design, the RVP is more general than SAMW. Deepening of the thermocline driven by heave in the subtropical gyre will significantly impact the RVP, while potentially not actually changing the heat content of recently subducted SAMW (defined between two isopycnals) at all. We must be careful not to conflate the RVP as defined here with the upper limb of the overturning circulation. However, this is not to say that this analysis tells us nothing about subduction. Gao et al. (2018), for example, show that the majority of recent heat uptake by SAMW is driven not by a change in the SAMW properties but instead by a thickening of the layer, largely driven by changes in wind forcing and subduction in the regions of deep mixed layers. This aligns well with the findings in the forward runs (Figure 6) where the subduction experiment over the SAMW formation regions is more impactful on RVP heat content than the high-latitude experiment. Further analysis of this distinction in the adjoint of a model defined on isopycnal surfaces would be revealing and we may expect to see a weaker response to fluxes over the subtropical gyre, but is beyond the scope of the present work.

Although changes in isopycnal layer thickness are not represented in the adjoint sensitivity fields, they are of course present in the "forward" step response experiments. As expected, all three "positive" step response forcing patterns induce warming on a representative interior isopycnal, with the warming being most widespread for the gyre forcing pattern (Figures 13a-13c). However, the changes in layer thickness between $26.9 \sigma_{0}$ and $27.2 \sigma_{0}$ are complex and regional. The gyre forcing pattern induces a thin band of concentrated thickening along the southern boundary of the RVP and a less concentrated thinning on the northern boundary of the RVP, due in part to asymmetries in the deepening and shoaling of isopycnals across the RVP (Figure 13d). The high-latitude forcing pattern induces mild layer thickening along the southern boundary of the RVP that largely comes from the shoaling of the $26.9 \sigma_{0}$ isopycnal (Figure $13[\mathrm{e}]$ ). Finally, the "subduction" pattern induces thickening along the southern boundary of the RVP and thinning over a large fraction of the interior RVP (Figure 13f).

\subsection{Model Limitations}

Ocean-only configuration. ECCOv4-r2 is based on an instance of MITgcm in ocean-only mode. In this ECCOv4-r2 setup, the 2-m air temperature, 2-m specific humidity, downward shortwave radiation, and downward longwave radiation are specified as time-evolving boundary conditions. These atmospheric variables are inputs in the bulk formulae, which use differences between the fixed, specified atmospheric variables, and the dynamically evolving surface ocean state to determine the rates of air-sea heat exchange. 


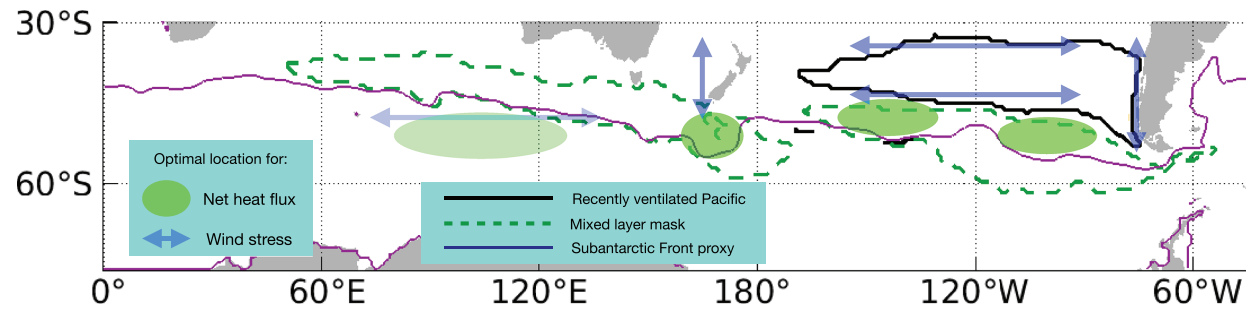

Figure 14. Summary schematic of which processes are most important for changing RVPh, along with the locations with the highest sensitivities. This schematic could be used, for example, to help select optimal locations for numerical perturbation experiments or observational data analysis studies. Due to the fact that the RVP is more general than SAMW, these results will be relevant for SAMW evolution as well. The regions in the Indian sector are more transparent because they are expected to produce weaker responses, at least on the 10-year timescale, compared with perturbations in the Pacific sector.

One consequence of this arrangement is that the sea surface temperature tends to be overly sensitive to changes in surface heat flux anomalies (Hyder et al., 2018). This heightened sensitivity arises from the fact that while the air-sea fluxes can respond to a change in ocean surface temperature, the atmospheric variables, for example, the given values of humidity and downward radiative fluxes, cannot. For a given flux perturbation (or forcing error) the $\mathrm{T}$ signal is $>5$ times smaller for an ocean-only model than for a coupled model (Hyder et al., 2018). So our heat flux sensitivities may be underestimates relative to the full coupled system. However, this bias mainly occurs at the surface, and it mainly occurs outside of the region of the perturbation. Once the anomalously warm/cool water comes into contact with the atmosphere away from the forcing perturbation, the anomaly can be rapidly damped away. It should not affect sensitivities to interior anomalies. Additional perturbation experiments in a coupled ocean-atmosphere model would be a welcome addition to this study.

Resolution. The mixing properties of ECCOv4 compare well with observations (better than some higher-resolution models), thanks in part to its optimized, spatially varying mixing coefficients (Forget, Campin et al., 2015). The mode water export pathways, as revealed by relatively low values of potential vorticity in the thermocline (not shown), compare well with those of the eddy-permitting Southern Ocean State Estimate (SOSE), which features (1/6) ${ }^{\circ}$ horizontal resolution (Jones et al., 2016; Mazloff et al., 2010). This agreement suggests that the ventilation properties of ECCOv4 are in broad agreement with observations and high-resolution state estimates. That being said, it would be instructive to repeat the sensitivity studies presented in this paper using a higher-resolution adjoint model (e.g., SOSE). At present, SOSE covers a maximum of 6 years, so the resulting sensitivity time series within the observationally constrained period would be shorter than those presented in this work.

We offer some preliminary thoughts on how our results may differ in a higher-resolution configuration. Numerical wind stress perturbation experiments suggest that as the resolution of an ocean model is increased, the added energy from a wind stress perturbation tends to transfer increasingly into the eddy field, as opposed to ending up in the mean flow (Munday et al., 2013). Because ECCOv4 is relatively coarse, it may overestimate the sensitivity of mean transport to changes in wind stress. As a result, our wind stress sensitivities may be overestimates. However, we would not necessarily expect the spatial patterns of the sensitivities to change substantially with increasing resolution, since many of our sensitivity dipoles indicate the relevance of Ekman transport, which will remain effective even in an eddy-resolving regime. Because the mixing and ventilation properties are already reasonably well-constrained in ECCOv4, we suspect that our heat flux sensitivities would not change substantially with increasing resolution.

\section{Conclusions}

We have used an observationally constrained adjoint model to identify the locations and timescales on which surface forcing can have the largest impact on the heat distribution in the recently ventilated eastern Pacific sector of the SO. Specifically, we find that the heat content of the fixed control volume (RVPh) is strongly affected by forcing and properties associated with the eastern SPG. On timescales shorter than 3-5 years, $\mathrm{RVPh}$ is most sensitive to wind stress anomalies that lie roughly on the borders of the RVP footprint, as Ekman transport can induce Ekman pumping/suction and thereby produce isopycnal heave that moves 
heat into and out of the fixed volume RVP. In addition, changes in large-scale gyre circulation can change heat convergence in the RVP through variations in the barotropic gyre circulation. On timescales longer than 3-5 years, RVPh is strongly affected by upstream heat flux anomalies. In the Pacific sector, these scaled sensitivities tend to be located south of the RVP projection and north of the SAF proxy, but still in the region of deep mixed layers. In the Indian sector, these scaled sensitivities can be found south of the SAF proxy, indicating the possible location of cross-frontal transport that can ultimately impact RVPh.

Based on the scaled and unscaled sensitivity fields (see the supporting information), we can recommend locations for optimal perturbation experiments in numerical models, including higher-resolution cases, that should produce especially large variations in RVPh relative to perturbations in other regions (Figure 14). In particular, we suggest that wind stress anomalies be applied at (1) the boundaries of the surface projection of the RVPh, including along the west coast of South America, (2) along the west coast of New Zealand, or (3) south of the SAF (or a suitable proxy) in the Indian sector, approximately in the longitude stretch between India and western Australia. In terms of net heat flux perturbations, in the Pacific sector we suggest applying perturbations south of the RVP surface projection and north of the SAF (or a suitable SSH proxy), while still in the region of deep mixed layers. In the Indian sector, we suggest perturbations (1) south of New Zealand and north of the SAF or (2) just south of the SAF proxy. The comprehensive sensitivity study carried out here suggests that RVPh is only weakly sensitive to net heat flux or wind stress anomalies south of the SAF on the 10- to 15-year timescales considered here.

\section{Appendix A: Separating Linear and Nonlinear Responses}

We separate the linear and nonlinear responses of a given quantity by imposing positive and negative perturbations of the same magnitude in two different model runs following Verdy et al. (2014) and Jones et al. (2018). Given a perturbation $\Delta Q=Q-Q_{0}$, in a quantity $Q$, then the response of a variable $H(Q)$ can be approximated by Taylor series expansions as:

$$
\Delta H=H-H_{0}=\frac{\partial H}{\partial Q}\left(Q-Q_{0}\right)+\frac{1}{2} \frac{\partial^{2} H}{\partial Q^{2}}\left(Q-Q_{0}\right)^{2}+\ldots,
$$

where $H_{0}$ and $Q_{0}$ are reference values about which the partial derivatives are evaluated. We denote the response to a positive perturbation $Q>Q_{0}$ as $\Delta H_{+}$and the response to a negative perturbation $Q<Q_{0}$ as $\Delta H_{-}$. We then estimate the linear response by the difference $\left(\Delta H_{+}-\Delta H_{-}\right) / 2 \approx\left(\partial_{Q} H\right)\left(Q-Q_{0}\right)$ and the nonlinear response by the sum $\left(\Delta H_{+}+\Delta H_{-}\right) / 2 \approx 0.5\left(\partial_{Q Q} H\right)\left(Q-Q_{0}\right)^{2}$. This approach is expected to work well if the response function in question can be well represented by a Taylor series expansion and if the first two nonconstant terms capture the majority of the variability of that response function.

\section{Acronyms}

ACC Antarctic Circumpolar Current

AAIW Antarctic Intermediate Water

MLD Mixed layer depth

SPG South Pacific Gyre

RVP Recently ventilated Pacific sector of the Southern Ocean (fixed volume)

$\mathrm{RVPh}$ Heat content of the fixed volume RVP

SAF Subantarctic Front

SAMW Subantarctic Mode Water

SO Southern Ocean

SSH Sea surface height

\section{References}

Cerovecki, I., \& Mazloff, M. (2015). The spatiotemporal structure of diabatic processes governing the evolution of Subantarctic Mode Water in the Southern Ocean. Journal of Physical Oceanography, 46, 683-710. https://doi.org/10.1175/JPO-D-14-0243.1

Cerovecki, I., Meijers, A. J. S., Mazloff, M. R., Gille, S. T., Tamsitt, V. M., Holland, P. R., \& Tamsitt, V. M. (2019). The effects of enhanced sea ice export from the Ross Sea on recent cooling and freshening of the Southeast Pacific. Journal of Climate, 32(7), 2013-2035. https:// doi.org/10.1175/JCLI-D-18-0205.1 
Cerovecki, I., Talley, L. D., Mazloff, M. R., \& Maze, G. (2013). Subantarctic Mode Water formation, destruction, and export in the eddy-permitting Southern Ocean state estimate. Journal of Physical Oceanography, 43(7), 1485-1511. https://doi.org/10.1175/ jpo-d-12-0121.1

Cessi, P., \& Otheguy, P. (2003). Oceanic teleconnections: Remote response to decadal wind forcing. Journal of Physical Oceanography, 33(8), 1604-1617. https://doi.org/10.1175/2400.1

Dee, D. P., Uppala, S. M., Simmons, A. J., Berrisford, P., Poli, P., Kobayashi, S., et al. (2011). The era-interim reanalysis: Configuration and performance of the data assimilation system. Quarterly Journal of the Royal Meteorological Society, 137(656), 553-597. https://doi.org/ 10.1002/qj.828

Downes, S. M., Bindoff, N. L., Downes, S. M., Bindoff, N. L., \& Rintoul, S. R. (2009). Impacts of climate change on the subduction of mode and intermediate water masses in the Southern Ocean. Journal of Climate, 22(12), 3289-3302. https://doi.org/10.1175/2008JCLI2653.1

Fekete, B. M., Vorasmarty, C. J., \& Grabs, W. (2002). High-resolution fields of global runoff combining observed river discharge and simulated water balances. Global Biogeochemical Cycles, 16(3), 1042. https://doi.org/10.1029/1999GB001254

Forget, G., Campin, J. M., Heimbach, P., Hill, C. N., Ponte, R. M., \& Wunsch, C. (2015). ECCO version 4: An integrated framework for non-linear inverse modeling and global ocean state estimation. Geoscientific Model Development, 8(10), 3071-3104. https://doi.org/10. 5194/gmd-8-3071-2015

Forget, G., Ferreira, D., \& Liang, X. (2015). On the observability of turbulent transport rates by Argo: Supporting evidence from an inversion experiment. Ocean Science Discussions, 12(3), 1107-1143. https://doi.org/10.5194/osd-12-1107-2015

Frölicher, T. L., Sarmiento, J. L., Paynter, D. J., Dunne, J. P., Krasting, J. P., \& Winton, M. (2015). Dominance of the Southern Ocean in anthropogenic carbon and heat uptake in CMIP5 models. Journal of Climate, 28(2), 862-886. https://doi.org/10.1175/jcli-d-14-00117.1

Gao, L., Rintoul, S. R., \& Yu, W. (2018). Recent wind-driven change in Subantarctic Mode Water and its impact on ocean heat storage Nature Climate Change, 8(1), 58-63. https://doi.org/10.1038/s41558-017-0022-8

Gaspar, P., Gregoris, Y., \& Lefevre, J. M. (1990). A simple eddy kinetic energy model for simulations of the oceanic vertical mixing: Tests at station Papa and long-term upper ocean study site. Journal of Geophysical Research, 95(C9), 16,179-16,193. https://doi.org/10.1029/ JC095iC09p16179

Gent, P. R., \& Mcwilliams, J. C. (1990). Isopycnal mixing in ocean circulation models. Journal of Physical Oceanography, 20(1), 150-155. https://doi.org/10.1175/1520-0485(1990)020\&lt;0150:IMIOCM\&gt;2.0.CO;2

Hanawa, K., \& Talley, L. (2001). Mode Waters. In G. Siedler, \& J. Church (Eds.), Ocean circulation and climate, International Geophysics Series. (pp. 373-386). London, UK: Academic Press.

Herraiz-Borreguero, L., \& Rintoul, S. R. (2011). Subantarctic mode water: Distribution and circulation. Ocean Dynamics, 61(1), 103-126. https://doi.org/10.1007/s10236-010-0352-9

Hyder, P., Edwards, J. M., Allan, R. P., Hewitt, H. T., Bracegirdle, T., Gregory, J., et al. (2018). Critical Southern Ocean climate model biases traced to atmospheric model cloud errors. Nature Communications, 9(1), 3625. https://doi.org/10.1038/s41467-018-05634-2

Ito, T., Woloszyn, M., \& Mazloff, M. (2010). Anthropogenic carbon dioxide transport in the Southern Ocean driven by Ekman flow. Nature, 463, 80. https://doi.org/10.1038/nature08687

Iudicone, D., Rodgers, K., Schopp, R., \& Madec, G. (2007). An exchange window for the injection of Antarctic Intermediate Water into the South Pacific. Journal of Physical Oceanography, 37, 31-49. https://doi.org/10.1175/JPO2985.1

Jones, D. C., Forget, G., Sinha, B., Josey, S. A., Boland, E. J. D., Meijers, A. J. S., \& Shuckburgh, E. (2018). Local and remote influences on the heat content of the Labrador Sea: An adjoint sensitivity study. Journal of Geophysical Research: Oceans, 123, 2646-2667. https://doi. org/10.1002/2018JC013774

Jones, D. C., Meijers, A. J. S., Shuckburgh, E., Sallee, J.-B., Haynes, P., McAufield, E. K., \& Mazloff, M. R. (2016). How does Subantarctic Mode Water ventilate the Southern Hemisphere subtropics? Journal of Geophysical Research: Oceans, 121, 6558-6582. https://doi.org/ $10.1002 / 2016 \mathrm{jc} 011680$

Kalnay, E., Kanamitsu, M., Kistler, R., Collins, W., Deaven, D., Gandin, L., et al. (1996). The NCEP/NCAR 40-year reanalysis project. Bulletin of the American Meteorological Society, 77(3), 437-471.

Kara, A. B., Rochford, P. A., \& Hurlburt, H. E. (2003). Mixed layer depth variability over the global ocean. Journal of Geophysical ResearchOceans, 108(C3), 3079. https://doi.org/10.1029/2000JC000736

Karsten, R., \& Marshall, J. (2002). Testing theories of the vertical stratification of the ACC against observations. Dynamics of Atmospheres and Oceans, 36(1), 233-246. https://doi.org/10.1016/S0377-0265(02)00031-3

Khatiwala, S., Primeau, F., \& Hall, T. (2009). Reconstruction of the history of anthropogenic CO2 concentrations in the ocean. Nature, 462(7271), 346-349. https://doi.org/10.1038/nature08526

Large, W., \& Yeager, S. (2009). The global climatology of an interannually varying air-sea flux data set. Climate Dynamics, 33, 341-364. https://doi.org/10.1007/s00382-008-0441-3

Liu, L., \& Huang, R. (2012). The global subduction/obduction rates: Their interannual and decadal variability. Journal of Climate, 25, 1096-1115. https://doi.org/10.1175/2011JCLI4228.1

Losch, M., Menemenlis, D., Campin, J.-M., Heimbach, P., \& Hill, C. (2010). On the formulation of sea-ice models. Part 1: Effects of different solver implementations and parameterizations. Ocean Modelling, 33(1-2), 129-144. https://doi.org/10.1016/j.ocemod.2009.12.008

Lovenduski, N., \& Ito, T. (2009). The future evolution of the Southern Ocean $\mathrm{CO}_{2}$ sink. Journal of Marine Research, 67, 597-617. https:// doi.org/10.1357/002224009791218832

Lumpkin, R., \& Speer, K. (2007). Global ocean meridional overturning. Journal of Physical Oceanography, 37, 2550-2562. https://doi.org/ $10.1175 / \mathrm{JPO} 3130.1$

Marshall, J., \& Speer, K. (2012). Closure of the meridional overturning circulation through Southern Ocean upwelling. Nature Geoscience, 5(3), 171-180. https://doi.org/10.1038/ngeo1391

Mazloff, M. R., Heimbach, P., \& Wunsch, C. (2010). An eddy-permitting Southern Ocean state estimate. Journal of Physical Oceanography, 40(5), 880-899. https://doi.org/10.1175/2009jpo4236.1

Morrison, A., Hogg, A., \& Ward, M. L. (2011). Sensitivity of the Southern Ocean overturning circulation to surface buoyancy forcing. Geophysical Research Letters, 38, L14602. https://doi.org/10.1029/2011GL048031

Munday, D. R., Johnson, H. L., \& Marshall, D. P. (2013). Eddy saturation of equilibrated circumpolar currents. Journal of Physical Oceanography, 43(3), 507532. https://doi.org/10.1175/JPO-D-12-095.1

Naveira Garabato, A. C., Jullion, L., Stevens, D. P., Heywood, K. J., \& King, B. A. (2009). Variability of subantarctic mode water and antarctic intermediate water in the drake passage during the late-twentieth and early-twenty-first centuries. Journal of Climate, 22(13), 3661-3688 https://doi.org/10.1175/2009JCLI2621.1

Rintoul, S. R., \& England, M. H. (2002). Ekman transport dominates local air-sea fluxes in driving variability of Subantarctic Mode Water. Journal of Physical Oceanography, 32(5), 1308-1321. https://doi.org/10.1175/1520-0485(2002)032\&lt;1308:ETDLAS\&gt;2.0.CO;2 
Russell, J., Dixon, K., Gnanadesikan, A., Stouffer, R., \& Toggweiler, J. (2006). The Southern Hemisphere westerlies in a warming world: Propping open the door to the deep ocean. Journal of Climate, 19, 6382-6390. https://doi.org/10.1175/JCLI3984.1

Sabine, C., Feely, R., Gruber, N., Key, R., Lee, K., Bullister, J. L., \& Rios, A. F. (2004). The oceanic sink for anthropogenic $\mathrm{CO}_{2} . S^{\text {Science, }}$ 305(367), 367-371. https://doi.org/10.1126/science.1097403

Sallee, J., \& Rintoul, S. (2011). Parameterization of eddy-induced subduction in the Southern Ocean surface-layer. Ocean Modelling, 39 146-153. https://doi.org/10.1016/j.ocemod.2011.04.001

Sallee, J., Speer, K., Rintoul, S., \& Wijffels, S. (2010). Southern Ocean thermocline ventilation. Journal of Physical Oceanography, 40, 509-529. https://doi.org/10.1175/2009jpo4291.1

Sallee, J.-B., Matear, R. J., Rintoul, S. R., \& Lenton, A. (2012). Localized subduction of anthropogenic carbon dioxide in the Southern Hemisphere oceans. Nature Geoscience, 5(8), 579-584. https://doi.org/10.1038/ngeo1523

Sarmiento, J. L., Gruber, N., Brzezinski, M. A., \& Dunne, J. P. (2004). High-latitude controls of thermocline nutrients and low latitude biological productivity. Nature, 427(6969), 56-60. https://doi.org/10.1038/nature02127

Speer, K., \& Forget, G. (2013). Global distribution and formation of mode waters. In Ocean circulation and climate-A 21st century perspective, (p. 211-226). London, UK: Academic Press. https://doi.org/10.1016/B978-0-12-391851-2.00009-X

Speer, K., Rintoul, S., \& Sloyan, B. (2000). The diabatic Deacon cell. Journal of Physical Oceanography, 30(12), 3212-3222. https://doi.org/ 10.1175/1520-0485(2000)030\&lt;3212:TDDC\&gt;2.0.CO;2

Talley, L. (2008). Freshwater transport estimates and the global overturning circulation: Shallow, deep and throughflow components. Progress in Oceanography, 78(3), 257-303. https://doi.org/10.1016/j.pocean.2008.05.001

Verdy, A., Mazloff, M. R., Cornuelle, B. D., \& Kim, S. Y. (2014). Wind-driven sea level variability on the California Coast: An adjoint sensitivity analysis. Journal of Physical Oceanography, 44(1), 297-318. https://doi.org/10.1175/JPO-D-13-018.1 